UNIVERSIDADE DE BRASÍLIA - UNB

INSTITUTO DE CIÊNCIA POLÍTICA E DE RELAÇÕES INTERNACIONAIS XI CURSO DE ESPECIALIZAÇÃO EM RELAÇÕES INTERNACIONAIS

Lynette de Andrade Lobo

\title{
A INTERNACIONALIZAÇÃO DAS EMPRESAS BRASILEIRAS: \\ A NOVA GEOGRAFIA INTERNACIONAL E SUAS IMPLICAÇÕES NA POLÍTICA DE INTERNACIONALIZAÇÃO DA EMBRAPA, A PARTIR DE 2003
}

Brasília, 


\section{Lynette de Andrade Lobo}

\section{A INTERNACIONALIZAÇÃO DAS EMPRESAS BRASILEIRAS: A NOVA GEOGRAFIA INTERNACIONAL E SUAS IMPLICAÇÕES NA POLÍTICA DE INTERNACIONALIZAÇÃO DA EMBRAPA, A PARTIR DE 2003}

Monografia de conclusão do XI Curso de Relações Internacionais para o Instituto de Relações Internacionais da Universidade de Brasília, a ser apresentada como requisito parcial para o título de Especialista em Relações Internacionais

Professor Orientador: Prof. Dr. José Flavio Sombra Saraiva

Brasília, 


\section{AGRADECIMENTO}

À minha família, pela constante parceria e cumplicidade e ao meu amor pelo incentivo à ousadia e à sede de conhecimento que me movem a rumos inesperados.

Aos colegas de trabalho que acreditaram na minha capacidade de realização.

Aos professores e colegas do XI Curso de Relações Internacionais que, por meio da troca de conhecimentos e do debate tornaram realidade meu antigo desejo de ampliar as possibilidades de atuação na área.

Ao professor José Flávio Sombra Saraiva pela sua impressionante capacidade de encorajar, identificar e traduzir nossos interesses nem sempre manifestados. 


\section{RESUMO}

A presente monografia procura identificar como se deu o processo de internacionalização das empresas brasileiras públicas e privadas, tendo como ponto de partida sua inter-relação com o processo de globalização no mundo e no Brasil e a influência da política externa brasileira nesse processo. No caso da Embrapa procura-se verificar as etapas da sua internacionalização começando pelas ações de treinamento do seu quadro técnico nas universidades norte-americanas e européias, a adaptação desse conhecimento à realidade brasileira, a sua contribuição para o desenvolvimento da agricultura tropical a partir da adaptação dessas tecnologias, até a sua transformação em uma empresa detentora de conhecimento tecnológico, credenciada a atuar nas diversas regiões do mundo. Registra o crescimento da projeção internacional da empresa, devido à atuação dos escritórios de negócios e dos laboratórios virtuais no exterior, bem como por meio da sua participação em grande parte das ações de cooperação internacional do governo federal. Por fim, é possível constatar que o processo de internacionalização da Embrapa, iniciado na busca por especialização técnica em países do hemisfério norte, é agora caracterizado pela crescente transferência de conhecimento, especialmente por meio de cooperação técnica, a países em desenvolvimento do hemisfério sul que necessitam incorporar mais tecnologia para elevar a produtividade de sua agricultura.

Palavras-chave: Internacionalização. Embrapa. Agricultura tropical. Cooperação técnica. Política externa brasileira. 


\begin{abstract}
INTERNATIONALIZATION OF BRAZILIAN ENTERPRISES: A NEW INTERNATIONAL GEOGRAPHY AND ITS IMPLICATION TO EMBRAPA'S INTERNATIONALIZATION POLICY SINCE 2003
\end{abstract}

This final paper seeks to identify how the process of internationalization of the public and private Brazilian companies was performed, taking as a starting point their connection with the process of globalization in the world and in Brazil, and the influence of Brazilian foreign policy in this process. In the case of Brazilian Agricultural Research Corporation (Embrapa), the stages of its internationalization activities are demonstrated starting with the training of its scientists in North American and European universities, subsequently with the adaptation of this knowledge to the Brazilian reality, followed by the contribution of that process to the development of tropical agriculture based on the adaptation of technologies or generation of new ones, until its transformation into a company with technological expertise that accredited it to operate in different regions of the world. This paper also registers the growing international influence of the corporation due to the actions of business offices and virtual laboratories abroad, as well as through its participation in many of the initiatives of international cooperation of the federal government. Finally, it is possible to conclude that the process of internationalization of Embrapa, that was initiated with the search for technical expertise in the northern hemisphere, is now characterized by increased knowledge transfer, particularly through technical cooperation, to developing countries in the southern hemisphere that need to incorporate more technology to increase the productivity of their agriculture.

Key words: globalization. Embrapa. Tropical agriculture. Technical cooperation. Brazilian foreign policy. 


\section{LISTA DE FIGURAS}

FIGURA 1 - Acordos de cooperação internacional da Embrapa por região, período 1997-

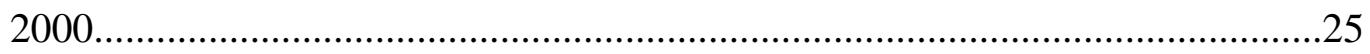

FIGURA 2 - Evolução da produção, área plantada e produtividade de grãos no Brasil, período

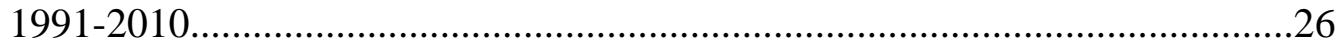

FIGURA 3 - Evolução do Balanço Social da Embrapa, período 1997-2008 .........................28

FIGURA 4 - Evolução do índice de retorno do capital investido na Embrapa, período 1997-

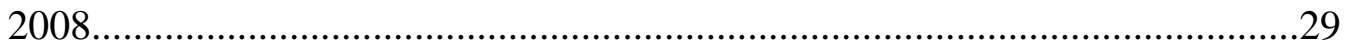

FIGURA 5 - Acordos de cooperação técnica da Embrapa, por região (\%) - 2008 . .37 


\section{LISTA DE TABELAS}

TABELA 1 - Ranking das empresas mais internacionalizadas em 2008..............................20

TABELA 2 - Projetos de cooperação técnica entre a Embrapa e instituições de países

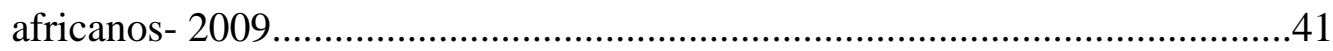

TABELA 3 - Projetos de cooperação técnica com países da América do Sul - 2009.............46 


\section{SUMÁRIO}

INTRODUÇÃO .................................................................................................................10

\section{CAPÍTULO 1 A INTERNACIONALIZAÇÃO DAS EMPRESAS E A POLÍTICA}

EXTERNA BRASILEIRA............................................................................................ 12

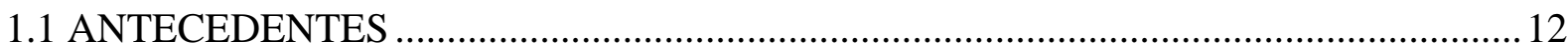

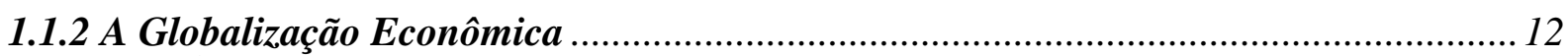

1.2 A POLÍTICA EXTERNA BRASILEIRA A PARTIR DE 2003 …………………........... 14

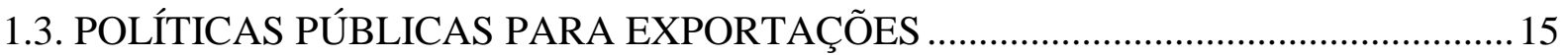

1.4. MODOS DE INTERNACIONALIZAÇÃO DE EMPRESAS ........................................... 16

1.5. PRINCIPAIS EMPRESAS QUE ATUAM NO MERCADO INTERNACIONAL ..........19

1.6 O PROCESSO DE INTERNACIONALIZAÇÃO DE EMPRESAS PÚBLICAS...............21

1.6.1 A Cooperação Técnica ........................................................................................... 21

CAPÍTULO 2 A INTERNACIONALIZAÇÃO DA EMBRAPA E A POLÍTICA EXTERNA DO GOVERNO LULA .......................................................................................24

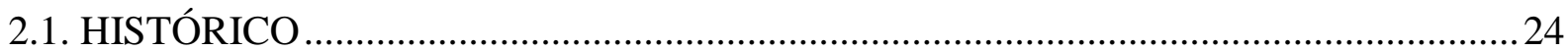

2.2. A EMBRAPA E O DESENVOLVIMENTO DA AGRICULTURA TROPICAL ............25

2.3 O DESEMPENHO DA EMBRAPA COMO EMPRESA BRASILEIRA …………...........22

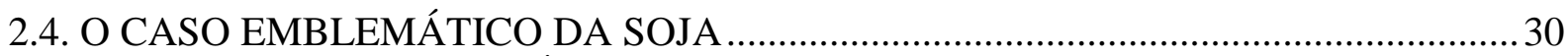

2.5. O CASO DOS LABORATÓRIOS VIRTUAIS NO EXTERIOR - LABEX …………........31

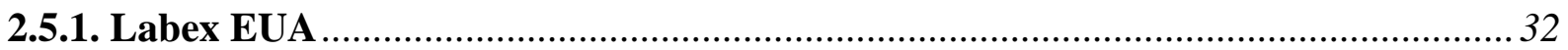

2.5.2. Labex Europa

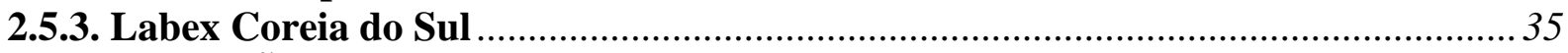

2.4 A ATUAÇÃO INTERNACIONAL DA EMBRAPA A PARTIR DE 2003........................37

CAPÍTULO 3 A EMBRAPA NAS REGIÕES............................................................39

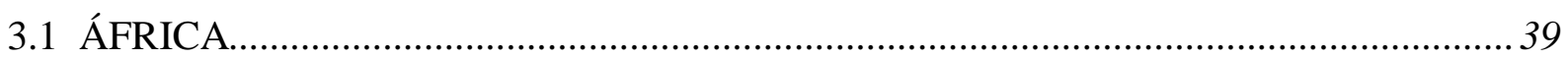

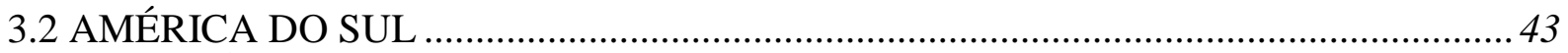

3.3 ESCRITÓRIO DA EMBRAPA NA VENEZUELA ……………………………............4

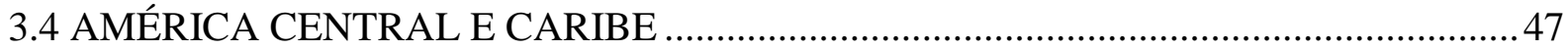

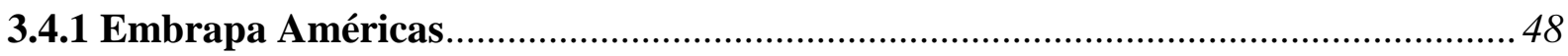

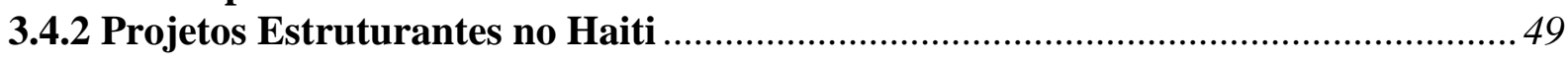

4 CONCLUSÃO....................................................................................................................50

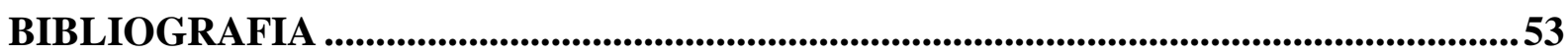




\section{INTRODUÇÃO}

A presente monografia procura identificar como se deu o processo de internacionalização das empresas brasileiras, com ênfase no caso Embrapa, para verificar a influência das ações da política externa do governo federal nesse processo.

Um grande número de empresas brasileiras vem buscando sua inserção no cenário internacional com o objetivo de expandir sua atuação em novos mercados. Há algumas décadas, jamais se poderia imaginar que empresas de prestação de serviços como a Mendes Júnior e a Andrade Gutierrez pudessem atuar no Oriente Médio e que a Petrobrás, a Vale do Rio Doce e a Perdigão aumentassem significativamente seus lucros atuando no mercado internacional. Até os anos 1990, empresas públicas do governo federal nunca sonhariam com a possibilidade de participar das ações de política externa, ampliando a sua área de atuação e contribuindo para a consolidação e o fortalecimento de instituições públicas de outros países.

Da mesma forma, a Diretoria da Embrapa, em 1973, quando tomou a iniciativa de estimular uma ampla especialização de seu quadro técnico, com o objetivo de buscar o conhecimento desenvolvido nas universidades da Europa e dos Estados Unidos para alavancar o desenvolvimento da pesquisa agropecuária brasileira, não poderia imaginar que isso pudesse revolucionar alguns setores da pesquisa agropecuária brasileira. Tal evolução ocorreria mediante a adaptação desse conhecimento à nossa realidade, tornando-a conhecida internacionalmente como empresa capaz de contribuir para o desenvolvimento da agropecuária em outros países.

A hipótese que se quer testar é de que o processo de internacionalização da Embrapa foi determinante para que a empresa deixasse de ser importadora de tecnologia para se tornar uma empresa exportadora de tecnologia, especialmente para países com condições de solo e clima semelhantes. Visa, ainda, a comprovar o papel da Embrapa na execução da política externa brasileira no que se refere à cooperação Sul-Sul.

O primeiro capítulo trata do processo de internacionalização de empresas brasileiras e identifica o processo de globalização nos seus diversos aspectos e períodos como principal responsável pela crescente onda de internacionalização que ocorreu em diversos países, especialmente sob influência da abertura dos mercados internacionais e da expansão do livre comércio ocorrido nos anos 1980. Identifica como esse processo aconteceu no Brasil e como as empresas brasileiras passaram a viabilizar sua internacionalização, sob a influência do contexto internacional e da política externa brasileira. 
Por sua vez, o segundo capítulo trata do processo de internacionalização da Embrapa, iniciado a partir do envio de um grande número de técnicos para especialização em universidades europeias e norte-americanas, visando à formação de competências adequadas às mudanças científicas e tecnológicas ocorridas nos países desenvolvidos com recursos externos. Demonstra a adaptação desse conhecimento à realidade brasileira e a maneira como o uso desse conhecimento adaptado transformou a agricultura no país tornando-a mais competitiva. Indica que o próximo passo foi a abertura de laboratórios virtuais no exterior, em parceria com instituições de pesquisa de renome, novamente com recursos internacionais. Finalmente, demonstra que o impulso recebido pela Embrapa, a partir de 2003, por meio da injeção de novos recursos e da inclusão da empresa em um grande número de missões oficiais, tanto com a participação do seu Diretor-Presidente em comitivas do Presidente da República, como com a inclusão de seus pesquisadores em missões da Agência Brasileira de Cooperação (ABC), consolidou a participação efetiva da empresa na execução da política externa brasileira.

O terceiro capítulo descreve as diversas ações que estão sendo executadas pela Embrapa em alguns continentes, procurando demonstrar que elas ocorrem em sintonia com o contexto político/diplomático das relações do Brasil com essas regiões. 


\section{Capítulo 1 A INTERNACIONALIZAÇÃo DAS EMPRESAS E A POLÍ́tiCa EXTERNA BRASILEIRA}

\subsection{ANTECEDENTES}

\subsubsection{A Globalização Econômica}

O processo de expansão de mercados para além das fronteiras nacionais começou no período dos grandes descobrimentos: no século $\mathrm{XV}$, com as expedições financiadas pelo Reino de Castilla e Aragón, em 1492, rompendo o isolamento entre o "Velho e o "Novo Mundo" e a consequente ampliação das relações, antes inexistentes, deu início à globalização. Novos componentes surgiram no século XIX, a partir da revolução industrial, com as inovações técnicas e tecnológicas nas indústrias e nos transportes, permitindo uma maior integração do mundo por meio da intensificação de trocas mercantis e do incremento de investimentos no estrangeiro.

No século XX, com a busca do aumento das condições de concorrência e da ampliação cada vez maior de mercados, houve um impulso no mundo inteiro da prática do liberalismo econômico. Assim sendo, observou-se, ao lado da abertura comercial generalizada, a difusão dos processos de desregulamentação e de privatização. Seguiu-se a esse processo a expansão acelerada das empresas multinacionais e de conglomerados financeiros. ${ }^{1} \mathrm{O}$ aumento vertiginoso dos fluxos comerciais e financeiros alavancou a internacionalização das empresas em todo o mundo 2 .

A industrialização brasileira ocorreu de fato a partir da segunda metade do século XX, e constituiu em um dos casos mais bem sucedidos, entre os países em desenvolvimento, do modelo de industrialização por substituição de importações, cuja inspiração intelectual foi a teoria de desenvolvimento da Comissão Econômica para a América Latina e o Caribe -

\footnotetext{
${ }^{1}$ O número de transnacionais em 1970 situava-se em torno de 7.000; já, em 1992, estimava-se esse número em 37.000 .

${ }^{2}$ MOLLO, Maria de Lourdes. 1977
} 
$\mathrm{CEPAL}^{3}$, cujas principais características eram forte indução estatal, relativa discriminação com relação às importações e participação do investimento estrangeiro nos diversos setores industriais.

Nos anos 1960 e 1970, adicionou-se um componente exportador a esta estratégia de desenvolvimento. A política externa foi um instrumento importante deste modelo, não apenas demandando tratamento diferencial no âmbito do regime de comércio e da constituição de um Sistema de Preferências Generalizado nos países desenvolvidos, assim como abrindo novos mercados e oportunidades de cooperação econômica nos países do $\mathrm{Sul}^{4}$.

No início dos anos 1980, acreditava-se que a abertura econômica era inevitável, uma vez que o processo de substituição de importações se esgotava. Desde então a liberalização comercial tornou-se o condutor das políticas econômicas dos países em desenvolvimento. Nessa mesma década, a economia brasileira passava por uma crise de endividamento externo, fazendo com que a política de comércio exterior estivesse voltada para a obtenção de superávits comerciais, restringindo importações e incentivando exportações (LACERDA, 2003, p. 203).

No final dos anos 1980, o quadro era de instabilidade e recessão, indefinição de política econômica e descontrole inflacionário, o que levou os agentes produtores a perceberem que o modelo deveria ser revisto, fato que já vinha acontecendo na maioria dos países da América Latina (LACERDA, 2003, p. 203).

Em função desse quadro de instabilidade, grande parte dos setores da economia brasileira encontrava-se em atraso tecnológico comparado com padrões internacionais. Esse atraso se manifestava tanto na obsolescência das máquinas quanto nos métodos administrativo-gerenciais e nas relações capital-trabalho (LACERDA, 2003, p. 207).

A liberalização comercial no Brasil teve como justificativa o desenvolvimento econômico, acarretando melhora na qualidade de vida da população em geral, consequência de uma otimização dos fatores de produção. Tal liberalização ficou mais intensa a partir de 1990, resultando em forte desindustrialização nacional e consequente aumento do desemprego. Outro resultado dessa abertura foi o aumento da oferta de produtos e serviços com preços e tecnologias mais acessíveis (LACERDA, 2003, p. 100).

\footnotetext{
3 A CEPAL foi criada em 1948 pelo Conselho Econômico e Social das Nações Unidas com o objetivo de incentivar a cooperação econômica entre os seus membros. Ela é uma das cinco comissões econômicas da Organização das Nações Unidas (ONU) e tem 44 estados e oito territórios não-independentes como membros. Além dos países da América Latina e Caribe fazem parte da CEPAL, o Canadá, França, Japão, Países Baixos, Portugal, Espanha, Reino Unido, Itália e Estados Unidos da América.

${ }^{4}$ LIMA, Maria Regina Soares. 2005
} 
A partir desse momento, ficou evidente a necessidade de fortalecimento e diversificação das relações de integrações regionais e mundiais, e o Brasil tornou-se um país mais ativo nessas questões logo no início dos anos 1990. Tais relações do comércio exterior brasileiro não se restringiram apenas à América do Sul, com determinação de fortalecer o Mercosul, merecendo destaque também a intensa discussão da integração continental através da Área de Livre Comércio da Américas - ALCA (ALMEIDA, 2001, p. 574), que ao final não se viabilizou. ${ }^{5}$

\subsection{A POLÍTICA EXTERNA BRASILEIRA A PARTIR DE 2003}

O presidente Lula, desde o início de seu mandato em 2003, propôs-se a trabalhar para "garantir uma presença soberana do Brasil no mundo", passando a estimular os diversos elementos de multipolaridade existentes na busca da democratização das organizações internacionais, em confronto, algumas vezes, com a política de governo dos Estados Unidos da América de afirmar cada vez mais um sistema unipolar, tendência mundial diante da globalização econômica marcada pelo apelo do livre-comércio. Diante desse complexo desafio, o governo passou a estimular a cooperação com países emergentes, desenvolvendo acordos bilaterais importantes com China, Índia e Rússia, além de desenvolver ações de fortalecimento do Mercosul e a cooperação com os países sul-americanos como estratégia de política regional, para consolidar a liderança brasileira e assim viabilizar a aspiração de incluir o país como membro do Conselho de Segurança da Organização das Nações Unidas.

Essa posição político-estratégica da política externa brasileira só foi possível graças às mudanças estruturais e sistêmicas acontecidas no Brasil, a partir do início dos anos 1990, com o esforço de abertura comercial iniciado na gestão do Presidente Fernando Collor, e pela adoção do Plano Real para a estabilização macroeconômica, na administração Itamar Franco, consolidado pelo governo Fernando Henrique Cardoso.

O país, que já tinha certo peso internacional como grande fornecedor de commodities minerais e agrícolas, a partir da estabilidade econômico-financeira e crescente influência regional, passou a atrair novos investimentos estrangeiros. A entrada de empresas

\footnotetext{
${ }^{5}$ CASSANO, Francisco Américo; NETO, Petrônio de Tilio; VORMITTAG, Carlos Francisco; JUNIOR, Amadeu Nosé; WIESEL, Raul Miguel. 2007
} 
multinacionais no país provocou uma maior concorrência no mercado interno, o que ocasionou um movimento natural de busca por novos mercados capazes de assimilar o produto brasileiro. A estratégia de exportação foi o primeiro passo para a internacionalização das empresas brasileiras, especialmente para aquelas voltadas ao setor de manufatura. ${ }^{6}$

\subsection{POLÍTICAS PÚBLICAS PARA EXPORTAÇÕES}

O governo brasileiro desempenhou um papel importante na tomada de decisão das empresas quanto à exportação, devido aos incentivos fiscais e creditícios oferecidos. Apesar desses incentivos terem sido fundamentais para o aumento das exportações, viabilizando o equilíbrio da balança comercial, não havia uma política explícita e articulada para tal. $\mathrm{O}$ diagnóstico das exportações brasileiras e o desempenho dos produtos nacionais nos mercados externos levaram o Governo a instituir a Agência Brasileira de Promoção de Exportações APEX, com o propósito de introduzir mudanças significativas nas políticas voltadas a estimular o comércio de produtos brasileiros no exterior.

Criada em novembro de 1997 por Decreto Presidencial, a APEX funcionou como uma Gerência Especial do Sebrae Nacional até 6 de fevereiro de 2003. Nesta data, passou a ser denominada APEX-Brasil, constituindo-se em um Serviço Social Autônomo ligado ao Ministério do Desenvolvimento, Indústria e Comércio Exterior. Dessa forma, a Agência ganhou autonomia, passando a desempenhar, no Governo Federal, a função de coordenar e executar a política de promoção comercial do país. O seu principal objetivo é o de inserir mais empresas no mercado internacional, por meio da diversificação da pauta dos produtos exportados, do aumento do volume vendido e da abertura de novos mercados, além de consolidar os atuais. Com essa estratégia, está sendo possível gerar mais renda e empregos diretos nas empresas nacionais ${ }^{7}$.

Desde 2003 o governo brasileiro tem concedido especial ênfase ao desenvolvimento de políticas voltadas para a construção da competitividade de longo prazo da economia brasileira. O primeiro passo nesse sentido foi a Política Industrial, Tecnológica e de Comércio

\footnotetext{
${ }^{6}$ SOUTO MAIOR, Luiz A. P. 2003

${ }^{7}$ www.apexbrasil.com.br/portal_apex/publicacao/engine.wsp?tmp.area=18. Acessado em março/2010.
} 
Exterior- PITCE, lançada no início do segundo ano do mandato inicial do presidente Lula. A PITCE produziu dois importantes resultados: a construção de um arcabouço legal-regulatório dedicado a promover a inovação, principalmente com a edição da Lei da Inovação (Lei 10.973/2004) e da Lei do Bem (Lei 11.196/2005); e o fortalecimento da estrutura institucional de apoio à política, com a criação do Conselho Nacional de Desenvolvimento Industrial (CNDI), instância de articulação público-privada com alto nível de representação, e da Agência Brasileira de Desenvolvimento Industrial (ABDI), além da reformulação da Agência Brasileira de Promoção de Exportações e Investimentos (APEX), subordinados ao Ministério do Desenvolvimento, Indústria e Comércio Exterior (MDIC).

Em maio de 2008, reafirmou-se a retomada de políticas de desenvolvimento industrial com o lançamento da Política de Desenvolvimento Produtivo (PDP), iniciativa que dá continuidade à PITCE, dando-lhe, porém, mais abrangência e potência. A PDP elegeu quatro macrometas para 2010, a saber: ampliar a taxa de investimento da economia brasileira para $21 \%$ do PIB, elevar o esforço de inovação no setor privado com o valor representando 0,65\% do PIB; ampliar a participação do País nas exportações mundiais, atingindo 1,25\%; e aumentar o número de micro e pequenas empresas exportadoras em $10 \%$.

Portanto, das quatro macrometas estabelecidas pela PDP, duas dizem respeito às exportações, o que reforça a estratégia política do governo brasileiro de promover a inserção internacional de empresas brasileiras ${ }^{8}$.

\subsection{MODOS DE INTERNACIONALIZAÇÃO DE EMPRESAS}

O processo de internacionalização de uma empresa começa a se desenrolar quando esta decide iniciar suas atividades em outro país, o que pode acontecer via controle total de ativos pela empresa entrante, ou por meio de operações de joint-ventures com empresas sediadas no país onde pretende ingressar. A exportação é o modo mais direto de internacionalização de atividades de uma empresa com custos mais reduzidos. A exportação pode ser direta, quando a empresa vende diretamente a um importador de um país estrangeiro, ou indireta, com a empresa vendendo a um intermediário do país de destino.

\footnotetext{
${ }^{8}$ www.abdi.com.br/?q=node/292. Acessado em março/2010
} 
Já a contratação inclui diversos arranjos contratuais, normalmente envolvendo alguma forma de cooperação entre as empresas que se pretendem internacionalizar. Isto pode ser feito através de licenciamento, no qual uma empresa cede para outra o direito de utilização da tecnologia, em troca do pagamento de royalties. Pode ser feito também por meio de franchising, tipo particular de licença ou contrato de assistência através do qual uma empresa obtém de outra o direito de explorar um produto, serviço, nome ou marca registrada. Ainda em contratação, têm-se o contrato de gestão, acordo que assegura a uma empresa a criação total ou parcial de uma unidade de negócio no exterior cedendo sua gestão a uma empresa independente, e, por fim, a subcontratação internacional, na qual a empresa principal encomenda à subcontratada alguns produtos, partes de produtos ou até mesmo operações dos mesmos.

Outro modo de entrada nos mercados internacionais seria o investimento direto, que engloba os investimentos efetuados com a finalidade de adquirir interesse duradouro em uma empresa que exerce a sua atividade no território de uma economia diferente da do investidor, dando-lhe poder decisivo de gestão na empresa. Por exemplo: uma joint-venture, que é a participação de várias empresas no capital de uma unidade econômica juridicamente independente; alianças estratégicas, que englobam várias situações de relações comerciais, e nas quais frequentemente as empresas são concorrentes; propriedade parcial, quando a empresa detém uma parte do capital, com poder de decisão em outra economia e, por fim, a propriedade total, que envolve a criação e/ou aquisição de uma subsidiária no estrangeiro (LORGA, 2003, p. 41-48)'.

A internacionalização produtiva é uma importante estratégia para contornar as restrições estabelecidas sobre a importação em diversos países, como a imposição de elevadas alíquotas tarifárias, de cotas, ou barreiras sanitárias. A opção por uma estratégia de inserção em mercados internacionais deve levar em conta os objetivos das empresas, além de dimensões estratégicas em relação a recursos e capacidades das mesmas, mas o fato é que atuar em variados mercados aumenta a capacidade de sobrevivência em face das dificuldades impostas pelo ambiente altamente competitivo da atualidade.

A evolução e as características do investimento brasileiro no exterior foram estudadas por alguns autores a partir da década de 1970, na tentativa de detectar as motivações e as

${ }^{9}$ CASSANO, Francisco Américo; NETO, Petrônio de Tilio; VORMITTAG, Carlos Francisco; JUNIOR, Amadeu Nosé; WIESEL, Raul Miguel. 2007 
restrições ou dificuldades que as empresas de capital nacional encontraram para avançar no processo de internacionalização. Dias (1994), Goulart, Brasil e Arruda (1994) e Lopez (1999) concordam que houve diversas fases no processo, com diferenças nas especificidades setoriais, nas motivações estratégicas, nas modalidades de financiamentos e nas formas de operacionalização do investimento. Também concordam que os determinantes dessas diferentes fases estiveram fortemente vinculados ao contexto macroeconômico do País, portanto, a estabilização econômica ou o processo de integração regional tiveram impacto considerável no processo de internacionalização das firmas brasileiras.

Em pesquisa conduzida pelo Banco Nacional de Desenvolvimento - BNDES (1995) ${ }^{10}$ observou-se que, à diferença dos anos 1970, quando apenas grandes empresas - com faturamento acima de US\$ 500 milhões - tinham investimentos no exterior, na década de 1980 havia uma participação significativa daquelas com faturamento entre US\$ 200 milhões e US\$ 500 milhões, e daquelas com faturamento inferior a 100 milhões. O estudo também constatou um aumento no número de subsidiárias instaladas no exterior, especialmente de subsidiárias produtivas. A participação da América do Sul como localização dos investimentos e a diversificação dos setores investidores da indústria de transformação também aumentaram.

O estudo do BNDES contou com respostas de 30 grandes grupos econômicos nacionais, que haviam instalado 101 subsidiárias no exterior entre o início da década de 1970 e 1994. Essas subsidiárias estavam concentradas nos setores de mecânica, material de transporte e construção, e foram, em sua maioria, resultado de compras ou de associações com firmas existentes.

O fortalecimento do poder de competição, graças à proximidade com o mercado consumidor, foi considerado a principal motivação para as empresas internacionalizarem suas unidades, seguido pela capacidade de suprir o mercado regional e pelas novas oportunidades de investimentos possibilitadas pela integração regional. De acordo com Goulart, Brasil e Arruda (1994), na primeira metade da década de 1990 a abertura econômica estimulou um processo de reestruturação empresarial, e houve, simultaneamente, uma nova fase de internacionalização exportadora das empresas manufatureiras.

A diversificação do porte das empresas com investimentos no exterior, já apontada pela pesquisa do BNDES para a década de 1980, acentuou-se ainda mais na década seguinte, e a localização dos investimentos concentrou-se nos países do Cone Sul (mais de 50\% do total 
investido no período). Em ambos os períodos estudados, a construção foi o setor individual com maior número de instalações de unidades no exterior. A proporção de empresas de faixas menores de faturamento aumentou, fazendo com que o grupo respondesse por $53 \%$ dos investimentos realizados no exterior entre 1990 e 1994.

Uma das principais razões para a realização de investimentos no exterior para uma firma era a necessidade de estabelecer parcerias com as empresas compradoras, em razão das mudanças nas relações ocorridas entre as empresas e seus fornecedores, revelou o estudo.

Nesses casos, a instalação de uma subsidiária no exterior era uma tentativa de solucionar os problemas tecnológicos e de especificação do produto. Conforme as necessidades de seus clientes, as empresas optaram por estabelecer escritórios comerciais no exterior ou acordos de pesquisa e desenvolvimento tecnológico, pela realização de joint ventures com empresas locais, ou pela instalação de plantas de produção ou unidades de manutenção e reparos de peças. Grande parte desses investimentos estava localizada nos EUA, na Argentina e outros países da América Latina ${ }^{11}$.

\subsection{PRINCIPAIS EMPRESAS QUE ATUAM NO MERCADO INTERNACIONAL}

Apesar da crise mundial, os investimentos de empresas brasileiras no exterior atingiram em 2008 a segunda marca mais alta da história, alcançando US\$ 20,5 bilhões, contra os US\$ 7,07 bilhões registrados em 2007 - um crescimento de 190\%. As vinte maiores transnacionais do país empregam ao redor do mundo 142,3 mil funcionários, possuem $\mathrm{R} \$$ 199,52 bilhões em ativos fora do Brasil e renderam R\$ 134,92 bilhões em receitas no ano passado, aumentando seu nível de internacionalização, aponta pesquisa da Fundação Dom Cabral (Tabela 1).

Em 2008, 25,32\% das receitas dessas empresas vieram de fora do país, enquanto $27,52 \%$ de seus funcionários e $27,66 \%$ de seus ativos se encontravam no exterior. Em 2007, esses percentuais eram de 24,16\%; 24,94\% e 22,33\%, respectivamente. No ranking das 41 transnacionais brasileiras mais internacionalizadas, a Gerdau aparece na frente com $63 \%$ do

\footnotetext{
${ }^{10}$ BNDES, nov.1995

${ }^{11}$ CORRÊA, Daniela; LIMA, Gilberto Tadeu. 2007
} 
total dos seus ativos fora do país e mais de $50 \%$ de suas vendas e seus funcionários no exterior. Na segunda colocação, a Sabó tem $40 \%$ de suas vendas feitas fora do país, assim como $49 \%$ dos ativos e $33 \%$ dos empregados. Em terceiro lugar, a Marfrig foi a companhia que mais aumentou seus ativos fora do país. O crescimento foi de $358 \%$ em relação a 2007 . O boom deveu-se principalmente à aquisição de 20 subsidiárias na Europa e América do Sul no ano passado. Com os negócios, o frigorífico tem agora o maior índice de funcionários fora do Brasil, com quase $60 \%$ da força de trabalho no exterior.

“Adquirimos empresas sólidas com experiência de 40, 50 anos. Temos como estratégia nos diversificarmos tanto geograficamente, quanto na variedade dos produtos oferecidos", diz Ricardo Florence dos Santos, diretor de relação com os investidores da Marfrig. Aparecem também entre as dez mais internacionalizadas as seguintes empresas: Vale, Metalfrio, Odebrecht, Aracruz Celulose, Tigre, Artecola e Suzano Papel e Celulose.

Tabela 1. Ranking das empresas mais internacionalizadas em 2008

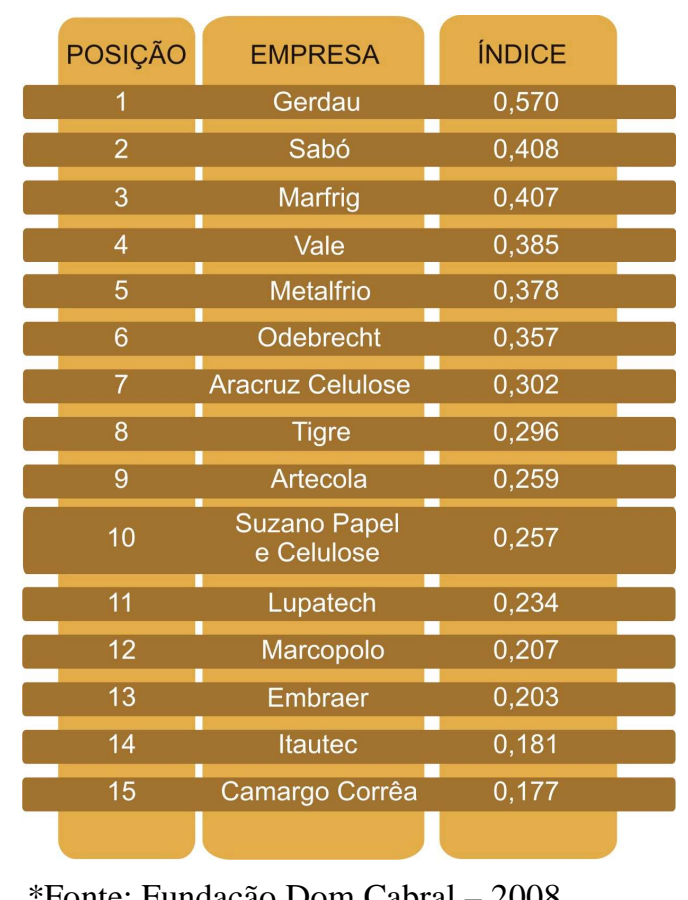

*Fonte: Fundação Dom Cabral - 2008

"Os grupos brasileiros transnacionais têm alto market share dentro do Brasil. Para poder continuar crescendo, eles precisam ir para o exterior", explica Jase Ramsey, coordenador do Núcleo de Internacionalização da Fundação Dom Cabral, que realizou a pesquisa. Das 41 empresas avaliadas pelo estudo, apenas 14, ou 35\%, diminuíram seu índice de internacionalização em 2008. 
As aquisições foram as principais responsáveis por aumentar o nível de internacionalização das empresas brasileiras em 2008. Cerca de $\mathrm{R} \$ 10,8$ bilhões foram direcionados a essas operações. Entre as mais importantes estão a compra da siderúrgica MacSteel, da Quanex Corporation, pela Gerdau, por US\$ 1,4 bilhão, e da alemã LWB Refractories, pela Magnesita, por US\$ 952 milhões.

Quando o critério são os ativos, a maior transnacional brasileira no exterior é a Vale (R 95 bilhões), seguida pela Gerdau ( $\mathrm{R}$ \$ 37,4 bilhões), Petrobras ( $\mathrm{R}$ \$ 26,53 bilhões), Votorantim ( $\mathrm{R}$ \$ 13,6 bilhões) e Odebrecht ( $\mathrm{R}$ \$ 8,1 bilhões). Juntos, os ativos das 20 maiores transnacionais do país no exterior cresceram 32\% em 2008 em relação a 2007, totalizando R \$ 201 bilhões $^{12}$.

\subsection{O PROCESSO DE INTERNACIONALIZAÇÃO DE EMPRESAS PÚBLICAS}

\subsubsection{A Cooperação Técnica}

O início das atividades de cooperação técnica internacional, como mecanismo auxiliar do desenvolvimento, ocorreu no final da Segunda Guerra Mundial, na conferência de Breton Woods, em julho de 1944, quando foram criados o Banco Mundial e o Fundo Monetário Internacional - FMI.

As primeiras iniciativas de estruturação da cooperação internacional regular como um todo (científica, técnica e tecnológica) foram motivadas pelas Nações Unidas devido à necessidade de reconstruir os países afetados pelo conflito e de acelerar o desenvolvimento dos países menos industrializados.

Em 1959, a Assembléia Geral da Organização das Nações Unidas - ONU decidiu rever o conceito de "assistência técnica", substituindo a expressão por "cooperação técnica", termo que era propício para definir uma relação que, se por um lado pressupõe a existência de partes desiguais, por outro representa uma relação de trocas, de interesses mútuos entre as partes.

\footnotetext{
${ }^{12}$ CAMPOS, Elisa. 2009
} 
Considerando-se que a carência de instituições adequadamente capacitadas constituía o principal empecilho para o desenvolvimento, a cooperação internacional deveria, portanto, conceder prioridade à capacitação institucional (“institution building”). A existência de instituições nacionais capacitadas tecnicamente (em administração pública, em planejamento, em ciência e tecnologia, em gestão de programas governamentais, etc.) foi trabalhada como condição essencial para que os esforços empreendidos tivessem continuidade posteriormente e para que os países recipiendários adquirissem a desejada autonomia.

A definição de instrumentos e mecanismos adequados para a implantação da cooperação internacional foi objeto de atenção especial desde o início. A ajuda financeira, o apoio técnico, a formação de recursos humanos, os processos de transferência de tecnologia, a doação de equipamentos e materiais, entre outros mecanismos, foram - e continuam sendo amplamente utilizados na operacionalização da cooperação. $O$ principal instrumento de definição das intervenções propostas e de planejamento das ações de cooperação é o projeto, consubstanciado em documento que registra os fins almejados e os meios necessários para sua consecução, além da lógica da intervenção (marco lógico, hipóteses feitas, riscos assumidos, responsabilidades compartidas, etc.).

Vários países desenvolvidos, instados pelas Nações Unidas, engajaram-se nos programas de cooperação, que tiveram continuidade mesmo após a etapa de reconstrução dos países mais afetados pela guerra. No entanto, à medida que se aprofundavam os interesses comerciais subjacentes, os empecilhos ao livre fluxo dos conhecimentos técnicos começaram a ficar mais evidentes. Neste cenário, a cooperação prestada pelos organismos internacionais passou a apresentar grande atrativo quando comparada à cooperação bilateral, que frequentemente limitava os assuntos passíveis de apoio pela cooperação técnica em função de políticas específicas dos países doadores. Os organismos internacionais - com destaque para o Programa das Nações Unidas para o Desenvolvimento - PNUD e para a Organização das Nações Unidas para o Desenvolvimento Industrial - ONUDI - viabilizaram a capacitação dos países em desenvolvimento em áreas estratégicas, recrutando especialistas disponíveis no mercado internacional para atuar nos projetos definidos e apoiando financeiramente sua implantação.

Na década de 1970, o acúmulo de experiências positivas dos países em desenvolvimento, passíveis de ser transferidas para outros países com problemas semelhantes, fez com que as Nações Unidas desenvolvessem o conceito e fomentassem a "cooperação técnica entre países em desenvolvimento - CTPD” ou “cooperação horizontal", em 
contraponto à "cooperação Norte - Sul”. Em 1974, foi criada a Unidade Especial para CTPD no âmbito do PNUD, iniciando-se os estudos para o fomento a essa modalidade de cooperação. Em 1978, as diretrizes elaboradas foram propostas na Conferência das Nações Unidas sobre Cooperação Técnica entre Países em Desenvolvimento e suas recomendações aprovadas na forma do Plano de Ação de Buenos Aires - PABA.

Desta forma, a cooperação técnica internacional - CTI configura-se como um instrumento auxiliar de promoção do desenvolvimento nacional e um importante mecanismo de estreitamento das relações entre países. Para contribuir para o processo de desenvolvimento socioeconômico, a CTI enseja a transferência de conhecimentos entre um organismo internacional e um país, ou entre países, em bases não comerciais, com vistas a alcançar objetivos previamente definidos e acordados entre as partes (consubstanciados em um Documento de Projeto), em um tema específico.

O estágio de desenvolvimento alcançado pelo Brasil, entre diversos países que vinham se beneficiando intensamente da cooperação internacional nas últimas décadas, fez com que algumas instituições brasileiras fossem demandadas com crescente intensidade tanto por países interessados na sua experiência quanto por organismos internacionais. Neste particular, o governo brasileiro, reconhecendo a importância que a CTI havia representado para o desenvolvimento nacional, considerou que o Brasil deveria dar um retorno compatível com os benefícios dela obtidos e colocou sua experiência à disposição dos países interessados.

A Agência Brasileira de Cooperação passou a realizar missões internacionais multidisciplinares para tratar das demandas pontuais dos países com os quais o governo brasileiro tinha intenção de estreitar laços diplomáticos, incluindo as diversas empresas brasileiras do Governo Federal nessas missões, com o objetivo de transferir conhecimento para alavancar o desenvolvimento desses países nos setores mais vulneráveis ${ }^{13}$. A Embrapa foi crescentemente demandada a participar dessas missões com o objetivo de contribuir para o desenvolvimento da produção agrícola e pecuária. Esse foi um dos passos rumo à internacionalização da empresa que será mais bem explorado no próximo capítulo.

\footnotetext{
${ }^{13}$ www.abc.gov.br/ct/historico.asp. Acessado em março/2010
} 


\section{Capítulo 2 A INTERNACIONALIZAÇÃO DA EMBRAPA E A POLÍTICA EXTERNA DO GOVERNO LULA}

\subsection{HISTÓRICO}

A Embrapa foi criada por decreto do governo federal, em 1973, com a missão de viabilizar soluções de pesquisa, desenvolvimento e inovação para a sustentabilidade da agricultura, em benefício da sociedade brasileira. A presença da Embrapa nos diversos estados brasileiros, por meio das 45 unidades de pesquisa por produtos e serviços e o seu quadro técnico altamente especializado, foi determinante para o desenvolvimento da agricultura tropical no País. O alto nível de especialização de seu quadro técnico se deu graças à decisão da diretoria da empresa em estimular a saída dos técnicos para fazer especialização nas principais universidades norte-americanas e européias, garantindo assim o acesso a tecnologias de ponta desenvolvida nesses locais. Graças a essa formação de qualidade e ao esforço dos pesquisadores em adaptar os novos conhecimentos à realidade brasileira, houve uma transformação na produção de diversos alimentos e matérias primas industriais.

Algumas parcerias surgiram como consequência do interesse das universidades e da Embrapa em validar as pesquisas desenvolvidas por ocasião dos cursos de pós-graduação realizados pelos técnicos da Embrapa nas universidades europeias e norte-americanas. Em decorrência disso foram assinados acordos com universidades. A Figura 1 abaixo demonstra a distribuição das parcerias internacionais em porcentagem, no período de 1997 a 2000, que confirmam a existência de um número maior de projetos com países do hemisfério norte, já que os principais parceiros eram as universidades estrangeiras ${ }^{14}$.

\footnotetext{
${ }^{14}$ Banco de dados da Secretaria de Relações Internacionais, Embrapa. 2009
} 


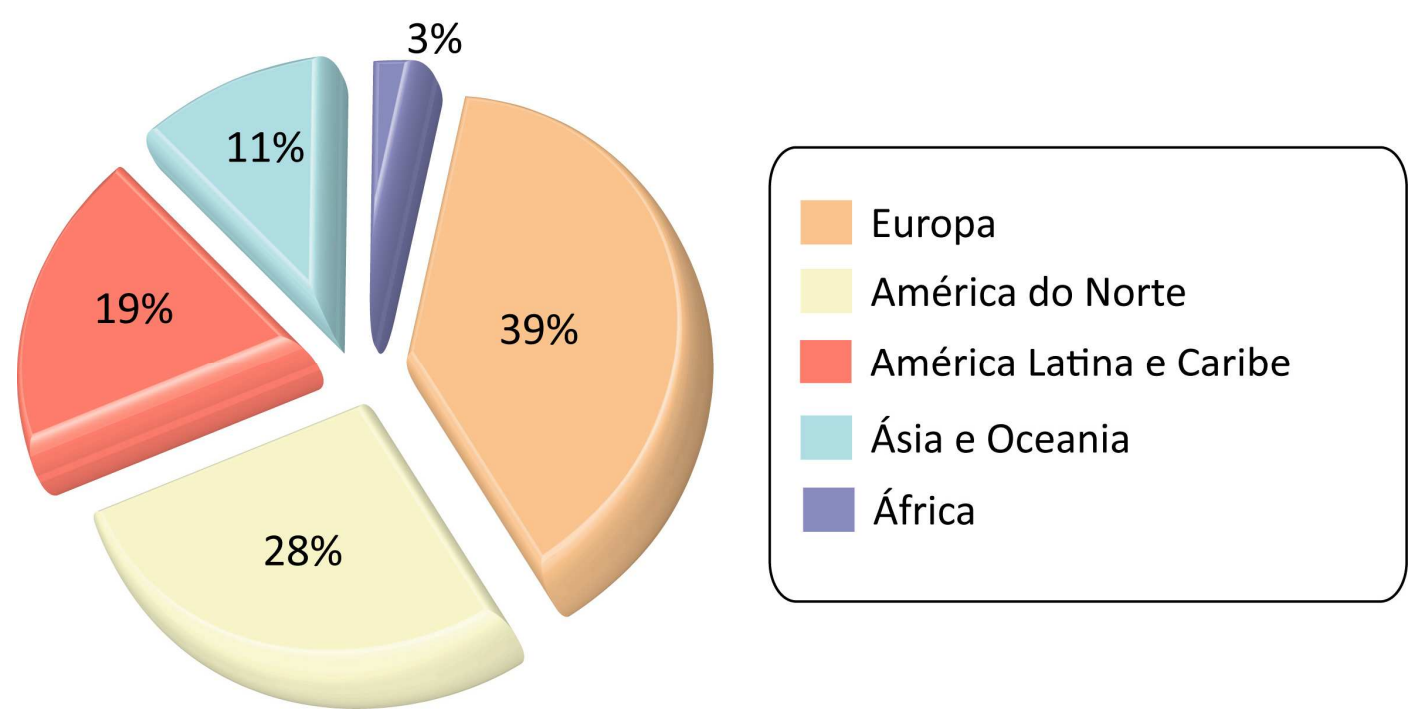

Fonte: Secretaria de Relações Internacionais da Embrapa.

Figura 1 - Acordos de cooperação internacional da Embrapa (\% por região) - Período 19972000

\subsection{A EMBRAPA E O DESENVOLVIMENTO DA AGRICULTURA TROPICAL}

Para ajudar a construir a liderança do Brasil em agricultura tropical, a Embrapa investiu, sobretudo, no treinamento de recursos humanos; conta atualmente com 8.692 empregados, dos quais 2.014 são pesquisadores - $21 \%$ com mestrado, $71 \%$ com doutorado e 7\% com pós-doutorado. O orçamento da empresa em 2009 foi de R\$ 1,685 bilhão.

O Sistema Nacional de Pesquisa Agropecuária - SNPA, sob a coordenação da Embrapa, constituído de instituições públicas federais, estaduais, universidades, empresas privadas e fundações, de forma cooperada, executam pesquisas nas diferentes áreas geográficas e campos do conhecimento científico. Com esta estrutura o SNPA tem gerado importantes resultados para a pesquisa agropecuária. Dentre as inúmeras tecnologias geradas destacam-se as responsáveis pela incorporação dos cerrados ao sistema produtivo, o que tornou essa região responsável pela produção de 67,8 milhões de toneladas de produtos agropecuários, ou seja, 48,5\% da produção do Brasil (2008). A soja foi adaptada às condições brasileiras e hoje o País é o segundo produtor mundial. A oferta de carne bovina e suína foi multiplicada por cinco vezes, enquanto que a de frango aumentou 21 vezes (período 1975/2008). A produção de leite aumentou de 7,9 bilhões, em 1975, para 27 bilhões de litros, 
em 2008, e a produção brasileira de hortaliças elevou-se de 9 milhões de toneladas, em uma área de 771,36 mil hectares, em 2005, para 17,5 milhões de toneladas, em 806,8 mil hectares, em 2006. Além disso, programas de pesquisa específicos conseguiram organizar tecnologias e sistemas de produção para aumentar a eficiência da agricultura familiar e incorporar pequenos produtores ao agronegócio, garantindo melhoria na sua renda e em seu bem-estar ${ }^{15}$.

Conforme dados da Figura 2, a produção de grãos no país cresceu, no período 1991$2010,148,7 \%$, o que representa um crescimento anual médio de 4,9\%. Por sua vez, a área plantada cresceu, no mesmo período, $25,9 \%$, com um crescimento médio anual de $1,2 \%$. No mesmo período, a produtividade de grãos dobrou, passando de 1,5 ton/ha a 3,5 ton/ha, com um aumento médio anual de 3,7\%. Por conseguinte, pode-se constatar que o aumento da produção de grãos se deveu muito mais ao aumento da produtividade que ao aumento da área plantada. Isto significa que com o aumento da produtividade não foi necessário aumentar mais a área plantada com grãos, destacando-se que o aumento da produtividade é resultado direto do aumento do nível tecnológico adotado pelos agricultores.

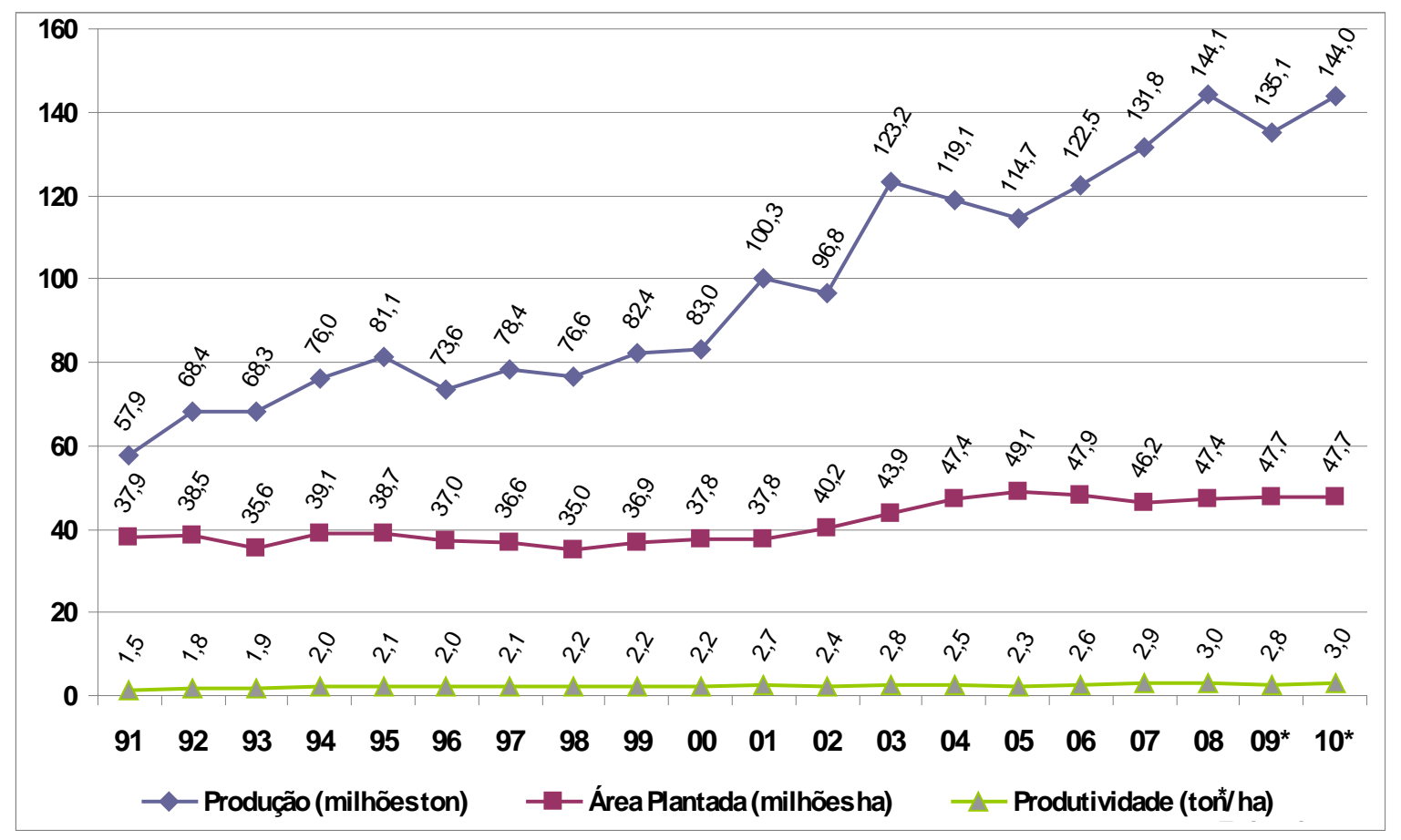

Fonte: MAPA/CONAB (2010) ${ }^{16}$

Figura 2. Evolução da Produção, Área Plantada e Produtividade de Grãos no Brasil, no período 1991-2010.

\footnotetext{
${ }^{15}$ :www.embrapa.br/a_embrapa/atuacao/ . Acessado em março/2010

${ }^{16}$ www.conab.gov.br/conabweb/index.php?PAG=131 (acessado em 19/03/2010).
} 


\subsection{O DESEMPENHO DA EMBRAPA COMO EMPRESA BRASILEIRA}

A Embrapa, a exemplo de outras organizações públicas brasileiras de pesquisa agropecuária, sempre teve dificuldade de justificar a sua existência para os gestores públicos, legisladores e para a sociedade em geral. Havia necessidade de demonstrar a sua importância como empresa, já que a pequena renda gerada com a venda de sementes básicas de cultivares desenvolvidas pela empresa não representa $5 \%$ do orçamento total. Havia também a necessidade de demonstrar o valor da Embrapa, identificar o seu maior patrimônio, os lucros que a empresa deveria gerar, já que não é uma S/A, não precisa publicar suas contas e o balanço contábil demonstra prejuízo financeiro.

Deste modo, os técnicos da Secretaria de Gestão e Estratégia - SGE - da Embrapa passaram a utilizar uma amostra de tecnologias, avaliada com metodologias de análise multidimensional de impactos, para demonstrar porque vale a pena investir em pesquisa agropecuária. Esta metodologia foi desenvolvida e é aperfeiçoada continuamente. Em 1997, foi apurado apenas o impacto econômico das tecnologias em termos de aumento da renda nacional e de economia e redução de custos de produção. Estes impactos econômicos passaram a ser detalhados para incluir incrementos de produtividade, redução de custos, expansão da produção em novas áreas, agregação de valor e também os custos da tecnologia e seu custo-benefício.

Em seguida, para cada tecnologia foram incorporados impactos sociais, como emprego, renda, saúde, gestão e administração, além de impactos ambientais, que consideram o alcance da tecnologia, sua eficiência tecnológica, a conservação ambiental e qualidade do produto. Por fim, a metodologia passou a avaliar os impactos do desenvolvimento e da adoção da tecnologia sobre o conhecimento, sobre processos de capacitação e aprendizagem, bem como impactos político-institucionais, seja na formulação de políticas públicas, nas relações com outras instituições ou na própria imagem da Embrapa.

O Balanço Social da Embrapa demonstra ainda que as tecnologias geradas e transferidas para a sociedade trazem um importante benefício econômico-financeiro, social e ambiental para a sociedade brasileira, que não é pouco, mas que também quase nunca apareciam nos demais documentos e relatórios publicados pela Embrapa. As ações sociais demonstradas no Balanço Social são atividades de pesquisa, desenvolvimento e transferência 
de tecnologias, produtos e serviços, em meio ambiente e educação ambiental, apoio comunitário, reforma agrária, participações no projeto fome zero, comunidades indígenas, segurança alimentar, educação e formação profissional, ações externas e internas, bem estar, segurança e medicina do trabalho e agricultura familiar realizadas durante o ano.

O conceito de Lucro Social apresentado no Balanço Social da Embrapa envolve insumos de três fontes. Os Impactos das Tecnologias Desenvolvidas e Transferidas à Sociedade, que são calculados segundo metodologia de análise multidimensional de impactos da Secretaria de Gestão e Estratégia da Embrapa. Os indicadores Laborais, que são calculados segundo metodologia proposta pelo Instituto Brasileiro de Análise Social e Econômica (Ibase) para os recursos investidos em: alimentação, encargos sociais compulsórios, previdência privada, saúde, segurança e medicina do trabalho, educação, creches/auxílio-creche e outros benefícios. E a terceira fonte são os indicadores Sociais, que são calculados segundo a metodologia proposta pelo Ibase e reúnem todos os tributos, excluídos os encargos sociais pagos no ano pela empresa.

Os resultados da Receita Operacional Líquida (ROL), dos Indicadores Laborais (IL), dos Indicadores Sociais (IS), do valor das Tecnologias Desenvolvidas e Transferidas (TD) e do Lucro Social (LS) da Embrapa, no período 1997-2008, são mostrados na Figura 3. Pode-se constatar que o TD e o LS são sempre crescentes no período, enquanto os outros valores (ROL, IL e IS) aumentam em proporção bem menor. Isso mostra que para uma empresa da natureza da Embrapa não se pode apenas analisar seu desempenho com base no balanço contábil, mas deve ser levado em conta todo o impacto que as tecnologias geradas causam no ambiente produtivo agropecuário e os benefícios trazidos para a sociedade brasileira.

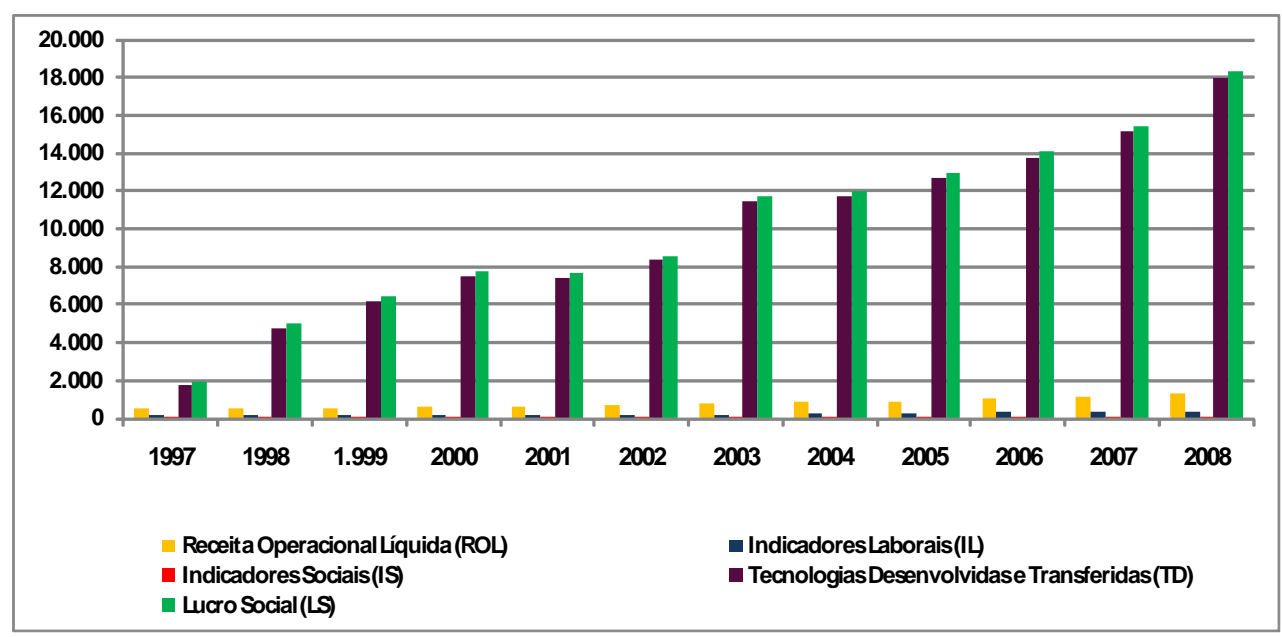

Fonte: indicadores dos Balanços Sociais anuais da Embrapa

Figura 3. Evolução do Balanço Social da Embrapa, no período 1997 - 2008. (valores R\$ x $1.000 .000,00)$ 
Em 2008, isto representou, respectivamente: $\mathrm{R} \$$ 17.963.808.262 (Impactos das Tecnologias); R\$ 379.127.955,46 (Indicadores Laborais); e R \$ 3.122.810,64 (Indicadores Sociais); Assim, o Lucro Social gerado pela Embrapa no ano de 2008 é calculado em R\$ 18.346.059.028,13. Esta é a principal contribuição do Balanço Social, qual seja, a de demonstrar que a Embrapa, por meio de suas atividades, gera benefícios para toda a sociedade brasileira, gera um lucro social, o que é bem diferente do prejuízo financeiro demonstrado e validado em seu balanço contábil.

A análise de benefício/custo $(\mathrm{B} / \mathrm{C})$ das atividades da Embrapa pode ser realizada utilizando-se diferentes enfoques metodológicos. A rentabilidade dos investimentos realizados na Embrapa pode ser calculada, por exemplo, pela taxa interna de retorno (TIR), um indicador tradicional de análise de investimentos. A taxa de retorno estimada foi de 37,5\%, o que comprova, mais uma vez, que os recursos investidos na empresa têm sido compensadores para a sociedade brasileira. De outro lado, adotando-se um enfoque contábil, podem-se calcular dois índices de retorno do capital investido na Embrapa. O primeiro, dividindo-se o valor dos Impactos das Tecnologias Desenvolvidas e Transferidas à Sociedade pela Receita Operacional Líquida (ROL), que representa tudo aquilo que passou pelos cofres da empresa no ano. O segundo, dividindo-se o Lucro Social pela ROL. Na Figura 4 é apresentada a evolução do retorno do capital investido na Embrapa por meio da relação entre o Lucro Social e a Receita Operacional Líquida.

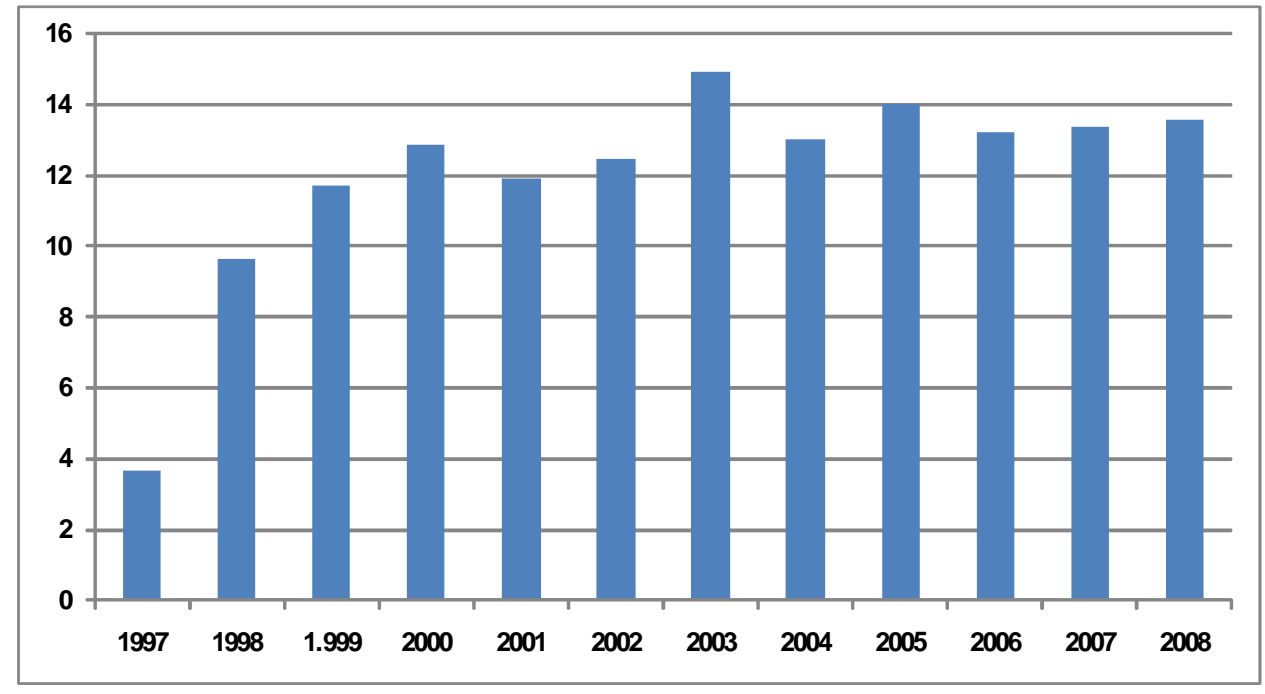

Fonte: indicadores retirados dos Balanços Sociais anuais da Embrapa.

Figura 4. Evolução do Índice de Retorno do Capital Investido na Embrapa, no período 19972008. 
Por exemplo, ao dividir-se o Lucro Social pela Receita Operacional Líquida da Embrapa no ano de 2008 obtém-se uma relação de 12,77 por um. Isto é, para uma receita da ordem de R \$ 1,06 bilhão em 2006, o lucro social representou mais de 12,77 vezes aquele valor. Ou seja, para cada real aplicado em 2008 na Embrapa, a empresa gerou para a Sociedade brasileira R 12,77 reais $^{17}$. Observa-se ainda na Figura 3 que o Índice de Retorno de Investimento na Embrapa tem permanecido ao redor de 1:13 nos últimos anos, o que significa que para cada real investido há um retorno de $\mathrm{R} \$ 13$ para a sociedade ${ }^{18}$.

\subsection{O CASO EMBLEMÁTICO DA SOJA}

“O crescimento da produção e o aumento da capacidade competitiva da soja brasileira sempre estiveram associados aos avanços científicos e à disponibilização de tecnologias ao setor produtivo. Até o final dos anos 1960, a pesquisa com a cultura da soja no Brasil era incipiente e concentrava-se na Região Sul do País, atuando, fundamentalmente, na adaptação de tecnologias (variedades, principalmente) introduzidas dos EUA. O primeiro programa consistente de pesquisa com a soja estabeleceu-se na década de 1950, no Instituto Agronômico de Campinas, SP. Mas foi no RS, uma década mais tarde, que a cultura encontrou condições para se estabelecer e expandir como lavoura comercial, para o que foi fundamental a boa adaptação que as cultivares introduzidas dos EUA tiveram para as condições do sul do Brasil.

O rápido desenvolvimento do cultivo da soja no País, a partir dos anos 60 , fez surgir um novo e agressivo setor produtivo, altamente demandante por tecnologias que a pesquisa ainda não estava estruturada para oferecer na quantidade e qualidade desejadas. Consequentemente, os poucos programas de pesquisa com soja existentes na região foram fortalecidos e novos núcleos de pesquisa foram criados no sudeste e centro-oeste, principalmente.

De todas as iniciativas para incrementar e fortalecer a pesquisa com soja no País, implantadas a partir dessa época, merece destaque a criação da Embrapa Soja, em 1975, que

\footnotetext{
${ }^{17}$ Informações da Secretaria de Gestão Estratégica da Embrapa. 2010

${ }^{18}$ www.embrapa.br/publicacoes/institucionais/folder_balancos_sociais/ . Acessado em março/2010
} 
patrocinaria, já a partir do ano seguinte, a instituição do Programa Nacional de Pesquisa de Soja, cujo propósito foi o de integrar e potencializar os isolados esforços de pesquisa com a cultura espalhados pelo sul e sudeste.

É conquista da pesquisa brasileira o desenvolvimento de cultivares adaptadas às baixas latitudes dos climas tropicais. Até 1970, os cultivos comerciais de soja no mundo restringiamse às regiões de climas temperados e subtropicais, cujas latitudes estavam próximas ou superiores aos $30^{\circ} \mathrm{C}$. Os pesquisadores brasileiros conseguiram romper essa barreira, desenvolvendo germoplasma adaptado às condições tropicais e viabilizando o seu cultivo em qualquer ponto do território nacional e transformando, somente no Ecossistema do Cerrado, mais de 200 milhões de hectares improdutivos em área potencial para o cultivo da soja e de outros grãos ${ }^{19}$.

\subsection{O CASO DOS LABORATÓRIOS VIRTUAIS NO EXTERIOR - LABEX}

Após o final dos anos 1980, com a falta de recursos para continuar investindo na formação em massa de seus técnicos, a direção da Embrapa passou a pensar numa maneira de continuar a monitorar de forma eficiente os avanços das fronteiras do conhecimento agropecuário em todo o mundo. Para isso foi criado um projeto para viabilizar o aumento da capacidade de detecção de inovação tecnológica e para a identificação de oportunidades de cooperação com os setores público e privado que realizam Pesquisa e Desenvolvimento agropecuário nos EUA e Europa.

O primeiro Labex (Laboratório Virtual no Exterior) foi criado em 1998, nos EUA, como um conceito inovador de colaboração internacional, para o desenvolvimento de projetos específicos de tecnologia de ponta ou de temática em centros de pesquisa e desenvolvimento (P\&D) de excelência. Esse modelo foi replicado na Europa em 2002, na França, e depois chegou à Holanda e Inglaterra. A utilização desse modelo de atuação da empresa fora do país aumentou a sua visibilidade, passando a existir um crescente reconhecimento internacional da sua competência como empresa de pesquisa agrícola.

19 www.cnpso.embrapa.br/producaosoja/SojanoBrasil.htm. Acessado em março/2010 
Os LABEX não possuem recursos físicos e humanos de um laboratório regular, compartilham com as instituições contrapartes instalações físicas, equipamentos, reagentes e equipes de pesquisadores. As equipes dos laboratórios trabalham para que as 45 unidades da Embrapa e os 100 centros de pesquisa dos órgãos de pesquisa nacionais e outras organizações de $P \& D$ estabeleçam novas parcerias e se integrem numa grande rede de pesquisa. Seus recursos disponíveis são racionalizados, ampliando a capacidade de proporcionar benefícios para a sociedade. Para financiar essa iniciativa são utilizados recursos de Acordos de Empréstimos internacionais, com um percentual de contrapartida nacional. Com dois anos e meio de execução, o sistema deflagrou notável mobilização e parceria institucional, que tem propiciado ganhos em eficiência no processo da pesquisa, na medida em que as instituições passam a compartilhar experiências (ganho mútuo de competência), a maximizar o uso dos recursos institucionais (reduzindo custos), a aumentar a sua produtividade e capacidade inovadora (fortalecendo-se institucionalmente) e a gerar conhecimentos e inovações técnicas mais factíveis e, portanto, com maiores chances de incorporação efetiva aos sistemas de produção. $^{20}$

\subsubsection{Labex EUA}

A cooperação da Embrapa com o Serviço de Pesquisa Agrícola do Departamento de Agricultura dos Estados Unidos - USDA/ARS, iniciada em 1998, tem hoje atividades nas áreas de agricultura de precisão, manejo integrado de enfermidades animais, manejo integrado de pragas e doenças de plantas, manejo de recursos do solo e da água, biotecnologia e propriedade intelectual, novos usos de produtos agrícolas e mudança global do clima.

Os principais resultados do Labex EUA são: assinatura de acordo entre a Fapesp e o USDA-ARS para o sequenciamento da bactéria Xylella fastidiosa, que ataca os laranjais do estado de São Paulo e as videiras do estado da Califórnia e publicação dos resultados finais do sequenciamento realizado pela rede genômica da Fapesp no Journal of Bacteriology, em fevereiro 2000; organização de informações referentes aos padrões de controle sanitário do rebanho bovino nacional para o Ministério da Agricultura do Brasil preparar sua defesa contra

\footnotetext{
${ }^{20}$ www.embrapa.br/imprensa/noticias/2003/maio/bn.2004-11-25.0940355939/?searchterm=labex
} 
as suspeitas do Canadá com respeito ao Mal-da-Vaca Louca, e da União Européia com respeito à Febre Aftosa; adaptação de um modelo computacional (PTF) para solos argilosos, predominantes em várias regiões brasileiras, que já vem sendo adotado no programa de zoneamento agrícola.

Com a adoção deste programa de forma mais ampla, poder-se-á expandir e, potencialmente, universalizar as bases de dados de solo e água, informações essenciais para a avaliação de riscos e sustentabilidade agrícola; identificação e classificação de tecnologias de agregação de valor em matérias-primas vegetais, especialmente soja e milho, desenvolvidas pelo ARS, passíveis de serem transferidas para a agroindústria nacional, tais como: tinta biodegradável, biocombustíveis, polímeros e bioplásticos; identificação de feromônios atrativos de insetos e parasitóides úteis no controle biológico de pragas de soja, milho e arroz; identificação de tecnologia de encapsulamento que protege e alonga a vida útil de agentes bioinseticidas utilizados no controle biológico de pragas de soja; articulação para viabilizar a transferência do Sistema Internacional de Informação de Insetos de Soja, o maior acervo bibliográfico sobre pragas de soja do mundo, para a Embrapa Soja; articulação para a doação de equipamento simulador de chuvas para estudos de dinâmica de nutrientes no solo e de qualidade de água para a Embrapa. Com este equipamento, a Embrapa Clima Temperado e a Embrapa Suínos e Aves montaram uma rede de estudos na área de manejo de dejetos e dinâmica de nutrientes em microbacias de SC e RS; adaptação e ajuste das condições brasileiras quanto a equipamentos agrícolas para uso com sensores de nutrientes no solo; identificação e validação de marcadores genéticos associados à resistência a doenças e parasitos em bovinos tropicais; articulação da participação da Embrapa no Consórcio Internacional de Construção do Genoma Bovino, coordenado pelo USDA-ARS; promoção do intercâmbio entre mais de 100 pesquisadores agrícolas brasileiros e americanos, através de visitas e missões técnicas a centros de pesquisas da Embrapa, ARS, institutos e universidades de ambos os países; articulação e promoção do sequenciamento de 6400 estruturas gênicas de gado zebu (Bos indicus) registradas no GenBank do NIH e do TIGR, bases de dados genéticos americanos, fruto do trabalho de tese de pesquisador da Embrapa Gado de Leite; treinamento de pesquisadores nas seguintes áreas do conhecimento: adaptação para aplicação na indústria brasileira de alimentos do programa de modelagem de patógenos (PMP), que é constituído de modelos matemáticos utilizados para prever o crescimento e antecipar a destruição de bactérias em alimentos; estabelecimento de um procedimento usando espectroscopia NIR e MIR combinada com PLSR para avaliar o teor de carbono em solos brasileiros; técnicas de 
processamento de imagens digital do satélite Aqua/AMSR-E para estimar umidade do solo; desenvolvimento de novas tecnologias para remover nitrogênio de dejetos suínos com baixo custo; desenvolvimento de novos materiais compostos à base de produtos agrícolas usando a nanotecnologia; nanofibras de celulose condutoras de eletricidade: nanotecnologia e alimentação: a resistência mecânica de filmes comestíveis, que em geral é muito pequena, pode ser significativamente melhorada com a utilização de quitosana preparadas por técnicas de nanotecnologia; métodos de biologia molecular foram utilizados para caracterizar patógenos alimentares para estabelecer seu relacionamento e identificar nichos em vários pontos da produção, ambiente de processamento e distribuição, e venda. Experimentos foram também conduzidos para validar tecnologias de processamento comercial para assegurar a segurança de alimentos prontos para consumo, inclusive de derivados lácteos.

\subsubsection{Labex Europa}

Na França, em conjunto com a Agropolis $^{21}$ de Montpellier, o Labex desenvolve pesquisas nas áreas de economia agrícola, biologia avançada, tecnologias agroalimentares e agroindustriais e gestão de recursos naturais. No seu primeiro ano de funcionamento, o Labex França tornou o Brasil o primeiro país em desenvolvimento do hemisfério Sul a ter um laboratório de pesquisa na Europa, junto a centros de excelência em ciência e tecnologia aplicadas à agricultura tropical.

Os pesquisadores brasileiros alocados na França tinham uma dupla função: realizar pesquisas estratégicas para a agricultura brasileira em laboratórios franceses de excelência, e fomentar a criação de uma científica e tecnológica, participando de um número máximo de encontros científicos nos seus domínios de competência.

Cada pesquisador, em sua área de competência, obteve avanços concretos que deram lugar a diversas publicações. Um dos resultados mais importantes alcançados pelo projeto, além das tecnologias desenvolvidas, é a credibilidade concedida à pesquisa brasileira na França, o que abriu possibilidades de participação de técnicos da empresa em diversos eventos científicos, além de ajudar a realizar novas parcerias com outras equipes. Os responsáveis pelas equipes que acolheram os pesquisadores brasileiros são hoje defensores da

\footnotetext{
${ }^{21}$ Centro de pesquisa francês, responsável por cooperação internacional agrícola com países em desenvolvimento.
} 
qualidade de cooperação com o Brasil. A presença do Labex em Montpellier e as redes de informação que seus pesquisadores teceram com os centros de pesquisa no Brasil constituem uma força de atração para numerosos estagiários brasileiros da Embrapa ou de outras instituições. Em resumo, o Labex desempenha um papel fundamental de promoção das relações científicas entre o Brasil, a França e a Europa.

A parceria com a França, no seu primeiro ano foi responsável pelos seguintes resultados: inserção de pesquisadores da Embrapa em projetos da Comissão Européia, liderado pelo Cirad $^{22}$, sobre agricultura sustentável no mundo; negociação e reconhecimento da propriedade intelectual do Banco Ativo de Germoplasma (BAC banana), desenvolvido junto ao Cirad-INIBAP; apoio à negociação de Acordo Técnico com a Associação de Produtores de Batata, para a realização de pesquisas no Brasil; articulação com pesquisadores franceses sobre interesses comuns na área de biotecnologia de café, cacau, algodão e bioinformática; projeto de valorização do pseudo fruto do caju, em colaboração com instituições francesas, Embrapa, ONGs e Governo de Benin (Africa).

\subsubsection{Labex Coreia do Sul}

O caso da Coreia do Sul é mais recente. As negociações para a abertura do Laboratório Virtual da Embrapa na Ásia tiveram início em 2005, quando Brasil e Coreia assinaram um memorando de entendimento para a cooperação entre as duas nações.

A criação do laboratório virtual coreano no Brasil e a instalação de um Labex Embrapa na Coreia é resultado de um acordo de cooperação bilateral assinado entre a Embrapa e a Agência de Desenvolvimento Rural da Coreia - RDA, em novembro de 2008. Existe um diferencial nessa iniciativa já que dois laboratórios serão implantados, um no Brasil e outro na Coreia do Sul. Um pesquisador da RDA trabalha na criação do RAVL laboratório virtual da RDA dentro da Embrapa, com um funcionamento similar ao Labex que a Embrapa mantém no exterior (Europa - Holanda, França e Reino Unido - e EUA) para desenvolver pesquisas em parceria com esses países em diversas áreas relacionadas à agropecuária. Esse trabalho será desenvolvido simultaneamente em duas frentes: i) coordenar as atividades administrativas do RAVL, e ii) integrar a equipe de reprodução animal da

\footnotetext{
${ }^{22}$ Centro de pesquisa francês, responsável por cooperação internacional agrícola com países em desenvolvimento.
} 
Embrapa Recursos Genéticos e Biotecnologia, uma das unidades de pesquisa da Embrapa cuja equipe é pioneira no Brasil no desenvolvimento de animais clonados por transferência nuclear e em várias outras tecnologias em prol da pecuária brasileira que vêm sendo repassadas ao setor produtivo, tais como: inseminação artificial; transferência, bipartição e sexagem (definição do sexo dos embriões antes do nascimento) de embriões; e fecundação in vitro (FIV). O pesquisador coreano trabalhava no Departamento e Genômica Animal e Bioinformática da RDA e a sua experiência será determinante para incrementar ainda mais os estudos de reprodução animal, especialmente dos relacionados à fertilização in vitro da Embrapa.

“A Coreia está bastante avançada no campo das ciências animais e eles já conseguem fecundar embriões de suínos in vitro, tecnologia que ainda não dominamos na Embrapa", explica o pesquisador Rodolfo Rumpf, da Embrapa Recursos Genéticos e Biotecnologia. Esse será um dos pontos altos da cooperação técnica. A fecundação de embriões in vitro já é feita com sucesso em bovinos no Brasil e a possibilidade de estendê-la para suínos vai beneficiar, especialmente, a conservação de raças em risco de extinção.

A Embrapa Recursos Genéticos e Biotecnologia mantém um programa de conservação de recursos genéticos animais, em parceria com outras unidades da Embrapa, instituições de pesquisa, universidades e associações de criadores, voltado à preservação de raças de animais domésticos ameaçadas de extinção. Muitas dessas raças, que englobam bovinos, suínos, ovinos, caprinos, equinos, asininos e bubalinos, encontram-se no Brasil desde o período da colonização e, por isso, possuem características de rusticidade e adaptabilidade adquiridas ao longo dos séculos, muito importantes para programas de melhoramento genético animal.

A RDA possui experiência sólida na área animal, tanto em termos de conservação quanto reprodução e, por isso, a troca de experiência com o pesquisador coreano será fundamental para as pesquisas da Embrapa. O trabalho do pesquisador da RDA é focado nas seguintes linhas de pesquisa: produção de embriões in vitro de bovinos e suínos; isolamento e cultivo de células somáticas; criopreservação (congelamento) de embriões e óvulos; genômica; clonagem por transferência nuclear e produção de animais transgênicos. Na Coreia, eles já dominam a tecnologia de produção de animais transgênicos, só que com o foco diferente do Brasil. Lá, a ênfase está na melhoria de qualidade da carne de bovinos e suínos, especialmente para produção de carne "marmorizada", de alta qualidade, entremeando fibras 
de gordura às fibras musculares. A cooperação prevê também o intercâmbio de cientistas brasileiros e coreanos. ${ }^{23}$

\subsection{A ATUAÇÃO INTERNACIONAL DA EMBRAPA A PARTIR DE 2003}

No Governo Lula, com a política externa privilegiando ações de fortalecimento da cooperação com países em desenvolvimento, especialmente com os do hemisfério Sul, houve um incremento da participação da Embrapa nas missões oficiais do Ministério de Relações Exteriores. É possível perceber na Figura 5, abaixo, que houve uma maior concentração de acordos e projetos de cooperação firmados com países em desenvolvimento, já que a empresa possui expertise para contribuir efetivamente para o desenvolvimento agrícola e pecuário desses países. Esses projetos de cooperação bilateral são financiados pelo PNUD, sob a coordenação da Agência Brasileira de Cooperação do Ministério das Relações Exteriores (MRE) e tem como objetivo transferir tecnologia para o melhoramento genético de sementes, a melhoria de técnicas de cultivo e de manejo de animais, o aprimoramento do processo produtivo, com ênfase no treinamento de técnicos estrangeiros, que passam a multiplicar esse conhecimento para formar equipes capazes de atuar no fortalecimento das instituições agrícolas.

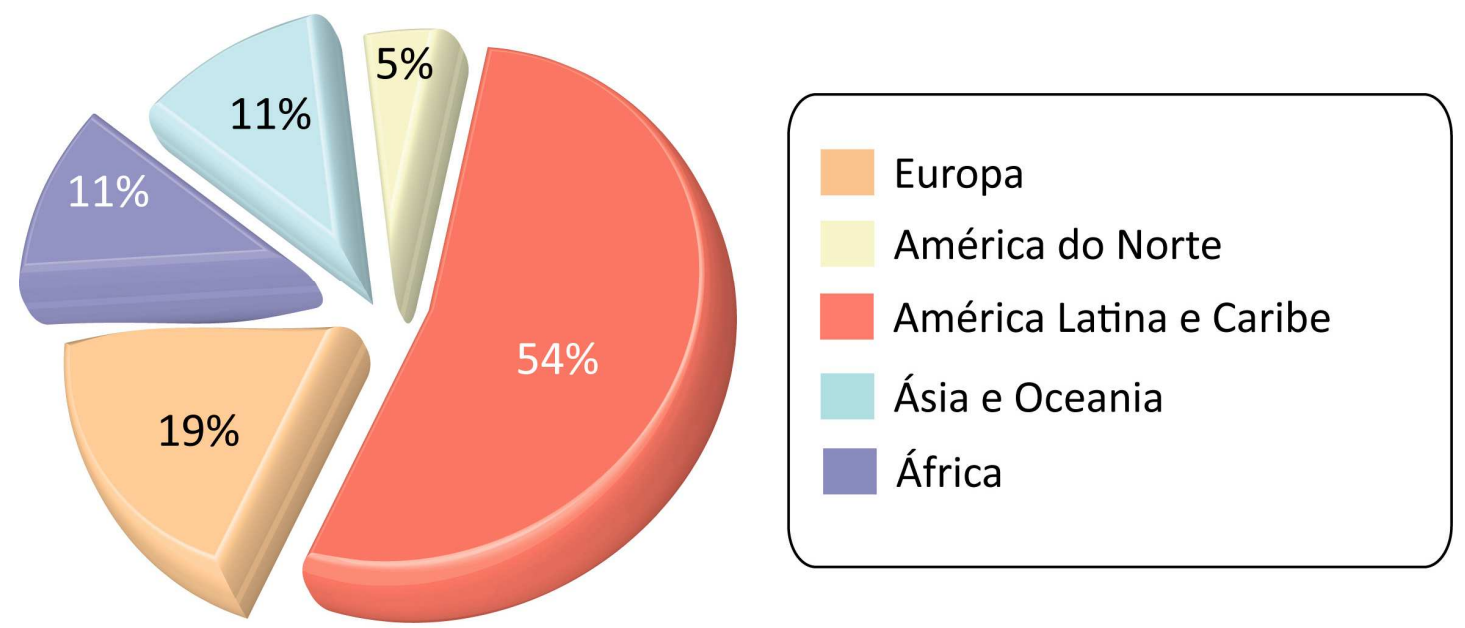

Fonte: Banco de dados da Secretaria de Relações Internacionais da Embrapa

Figura 5. Acordos de Cooperação Técnica da Embrapa, por região (\%) - 2008

\footnotetext{
${ }^{23}$ www.embrapa.br/imprensa/noticias/2009/marco/4a-semana/coreia-inicia-a-implantacao-de-laboratorio-virtualna-embrapa/?searchterm=labex coréia
} 
Diante do sucesso dessas ações pontuais, as instituições de pesquisa de alguns países em desenvolvimento demonstraram interesse às autoridades do governo federal na criação de unidades permanentes de demonstração, por meio da criação de instalações físicas da Embrapa no exterior, bem como na elaboração de projetos estruturantes. Assim sendo, foram instalados o escritório da Embrapa na África, em Gana, o Escritório de negócios em Caracas, na Venezuela, em parceria com a Agência Brasileira de Desenvolvimento Industrial - ABDI, o Laboratório virtual na Coréia do Sul, além da implantação de projetos estruturantes no Haiti e Mali. No primeiro semestre de 2010 será instalada a Embrapa Américas, no Panamá, além da implantação de projetos estruturantes no Haiti e Mali. 


\section{Capítulo 3 A EMBRAPA NAS REGIÕES}

\section{1 ÁFRICA}

O continente africano, exportador tradicional de matérias-primas e produtos agrícolas, vive até hoje dificuldades econômicas para sua inserção no novo contexto internacional do pós-Guerra Fria. De acordo com Pio Penna Filho: "esse continente, à exceção da África do Sul, possui uma estrutura econômica pouco diversificada, com ênfase na exportação de produtos primários, base produtiva relativamente fraca diante de um mundo globalizado". Esse problema tem consequências globais e foi agravado com os programas de ajuste estrutural levados a efeito pelo FMI e pelo Banco Mundial durante a década de 1980 e início da seguinte. Além disso, o continente sofre com as barreiras do protecionismo e subsídios agrícolas praticados pela Europa e pelos EUA, o que contribui para piorar o quadro econômico africano. Daí a existência de debate acerca da responsabilidade de países ricos em ajudar o continente africano na busca de soluções para os seus problemas ${ }^{24}$.

Apesar da ligação histórica entre o Brasil e o continente africano devido à miscigenação resultante do grande número de trabalhadores escravos que chegaram à época da colonização, além de uma história de dominação e exploração de riquezas, pouco se fez de concreto para aproximar Brasil e África ao longo dos anos. Até recentemente, essa relação foi marcada por ações esparsas, pouca comunicação entre os governos e longos períodos de silencio, por exemplo, durante o apartheid na África do Sul, entre os anos 1950 e 1990. Atualmente, o governo Lula tem se esforçado para incluir o continente africano na agenda da política externa brasileira. Isso não se dá por acaso: nos últimos anos, a política externa brasileira expandiu-se além da América do Sul, abrangendo outros países em desenvolvimento nos continentes africano, asiático e no Oriente Médio. Algumas ações importantes foram implantadas no Governo Lula para ampliar as relações culturais, científicas, comerciais, diplomáticas e políticas entre o Brasil e a África. Houve a intensificação da cooperação e da troca de experiências ${ }^{25}$.

\footnotetext{
${ }^{24}$ FILHO, Pio Penna. 2008

${ }^{25}$ BUENO, Chris. 2008
} 
A abertura de um escritório da Embrapa no continente africano responde ao desafio de transferir tecnologia na área agrícola para dar suporte ao desenvolvimento da agricultura, a partir da construção de programas em conjunto com os diversos países. A Embrapa África tem a missão de compartilhar conhecimento científico e tecnológico, colaborar no desenvolvimento da agricultura sustentável, com foco na transferência de tecnologia, na promoção e fomento do desenvolvimento social e do crescimento econômico dos países africanos, mediante o compartilhamento de conhecimentos e de experiências da agropecuária, de agroflorestas e de meio ambiente.

A equipe da Embrapa África, instalada em 2006 em Acra, Gana, conta com o suporte técnico e científico dos 45 centros de pesquisa, com mais de dois mil pesquisadores da empresa no Brasil, e desenvolve suas atividades em consistente articulação com as unidades da Embrapa, por intermédio da sua Secretaria de Relações Internacionais (SRI), a responsável pela elaboração do plano de trabalho e pela articulação da sua implantação, mediante aprovação da Diretoria da empresa.

A coordenação da execução dessas ações é feita pela Agência Brasileira de Cooperação - ABC, do Ministério de Relações Exteriores. As atividades desenvolvidas têmse concentrado na cooperação bilateral, por meio de projetos de cooperação técnica de atuação nas diversas áreas da agricultura, firmados entre as partes e amparados por acordos bilaterais entre os países, com ênfase na capacitação técnica para o fortalecimento das instituições e para o treinamento de recursos humanos. Esses projetos são, em geral, voltados para o desenvolvimento de capacidades locais, envolvendo instituições de pesquisa agropecuária governamentais, congêneres à Embrapa. São financiados com recursos da $\mathrm{ABC}$, com contrapartida de horas técnicas dos pesquisadores da Embrapa e de seus congêneres recipiendários da cooperação. Existem, ainda, ações de assistência técnica, na busca de parcerias com organismos doadores multilaterais e bilaterais, para viabilizar o financiamento de projetos agropecuários com tecnologia desenvolvida pela Embrapa, e de prospecção de oportunidades para o agronegócio brasileiro como é o caso da citada participação da Odebrecht no projeto Mali.

Além disso, o escritório da África participa de reuniões de Comissões Mistas de países africanos e atende aos pedidos das Embaixadas do Brasil naquele continente para identificar e priorizar demandas de cooperação na área de agricultura. A Tabela 2 apresenta um resumo 
dos atuais projetos de cooperação técnica firmados entre a Embrapa e instituições de 16 países africanos - Angola, Benin, Burkina Faso, Cabo Verde, Chade, Gabão, Gana, Guiné-Bissau, Mali, Moçambique, Nigéria, Quênia, São Tomé e Príncipe, Senegal, Tanzânia e Zâmbia - que estão em execução ou em fase final de negociação para assinatura.

Tabela 2. Projetos de cooperação técnica entre a Embrapa e instituições de países africanos

\begin{tabular}{|c|c|c|c|}
\hline PAÍSES & $\mathbf{N}^{\circ}$ & VALOR US\$ & STATUS \\
\hline ANGOLA & 1 & $7,381,430.00$ & Execução \\
\hline BENIN & 1 & $4,710,195.00$ & Execução \\
\hline BURKINA FASO & $\begin{array}{c}1^{*} \\
3\end{array}$ & $235,420.00$ & $\begin{array}{l}\text { Execução } \\
\text { Negociação }\end{array}$ \\
\hline CABO VERDE & 3 & $302,300.00$ & Execução \\
\hline CHADE & $1^{*}$ & - & Execução \\
\hline GABÃO & 1 & - & Negociação \\
\hline GANA & 4 & $488,664.12$ & Negociação \\
\hline GUINE-BISSAU & 1 & $25,000.00$ & Negociação \\
\hline MALI & $1^{*}$ & - & Execução \\
\hline MOÇAMBIQUE & $\begin{array}{l}2 \\
2\end{array}$ & $\begin{array}{r}186,185.00 \\
\text { - }\end{array}$ & $\begin{array}{l}\text { Execução } \\
\text { Negociação }\end{array}$ \\
\hline NIGÉRIA & 2 & $418,635.00$ & Negociação \\
\hline QUÊNIA & 3 & - & Negociação \\
\hline $\begin{array}{l}\text { SÃO TOMÉ E } \\
\text { PRÍNCIPE }\end{array}$ & 2 & $148,510.00$ & Negociação \\
\hline SENEGAL & $\begin{array}{l}2 \\
2 \\
\end{array}$ & $\begin{array}{r}2,317,089.00 \\
-\end{array}$ & $\begin{array}{l}\text { Execução } \\
\text { Negociação }\end{array}$ \\
\hline TANZÂNIA & 3 & - & Negociação \\
\hline ZÂMBIA & 3 & - & Negociação \\
\hline TOTAL & 35 & $16,213,128.1$ & - \\
\hline
\end{tabular}

Fonte: Resumo executivo. Secretaria de Relações Internacionais da Embrapa - 2009

*Projeto conjunto: Benin, Burkina-Faso, Chade e Mali

** Projeto conjunto: Guiné-Bissau e São Tomé e Príncipe

Como se pode observar pelo exame da Tabela 2, a Embrapa está desenvolvendo atividades com 16 países africanos por meio de 35 projetos que estão em execução, ou em fase final de negociação - nove projetos em execução, dos quais um de caráter regional envolvendo quatro países, e 26 projetos em fase final de negociação. O valor total desses projetos ultrapassa US\$ 16 milhões que serão desembolsados pelo Governo Brasileiro por meio da ABC, nos próximos três anos, a partir de 2009.

Os 26 projetos em fase final de negociação, com exceção de três projetos estruturantes (Apoio ao desenvolvimento da Rizicultura do Senegal, Programa de Parceria Japão-Brasil de Cooperação para o desenvolvimento das Savanas Africanas em Moçambique, e o Projeto de Cooperação triangular USAID-ABC-Embrapa para Países Africanos/Moçambique), são 
projetos pontuais e de curto prazo de duração, voltados para capacitação e treinamento de técnicos/especialistas dos países recipiendários da cooperação, sendo:

- sete projetos de capacitação em temas/especialidades da área de pecuária bovina leiteira e de corte (manejo de pastagens, manejo sanitário, melhoramento genético de raças, transferência de embriões, produção de sementes para pastagens, sistemas de produção, alimentação/nutrição animal) sob responsabilidade de execução da Embrapa Gado de Leite, da Embrapa Gado de Corte, e do Centro de Treinamento em Zebu de Leite, envolvendo o treinamento de 24 técnicos/especialistas africanos oriundos de Burkina Faso, Quênia, Senegal, Tanzânia e Zâmbia;

- dois projetos de capacitação em temas/especialidades da área de agroenergia e biocombustíveis (sistemas de produção de biocombustíveis e cultivos de biocombustíveis) sob responsabilidade de execução da Embrapa Agroenergia e da Embrapa Tabuleiros Costeiros, envolvendo o treinamento de 23 técnicos/especialistas africanos oriundos de Gana e Quênia;

- cinco projetos de capacitação em temas/especialidades na área de horticultura/olericultura e fruticultura - frutas tropicais e caju (produção sustentável de hortaliças, melhoramento genético, biotecnologia, manejo integrado de pragas, processamento agro-industrial, e tecnologia pós-colheita de hortaliças e de fruteiras/caju), sob responsabilidade de execução da Embrapa Hortaliças e da Embrapa Agroindústria Tropical, envolvendo o treinamento de 71 técnicos/especialistas, quatro africanos oriundos de Gana, Nigéria, Tanzânia, e treinamentos em Guiné-Bissau e São Tomé e Príncipe; e

- quatro projetos de capacitação em temas na área da cultura e processamento agroindustrial da mandioca (melhoramento genético, procedimentos laboratoriais de biotecnologia e manejo de recursos genéticos, manejo integrado de pragas, processamento agro-industrial e introdução de cultivares), sob responsabilidade de execução da Embrapa Mandioca e Fruticultura e da Embrapa Recursos Genéticos e Biotecnologia, envolvendo o treinamento de 48 técnicos/especialistas oriundos do Gabão, Gana, Nigéria, e São Tomé e Príncipe.

Existe ainda um projeto de longa duração, em fase de implantação, no campo experimental de Sotuba, em Mali, no valor de US\$ 1,5 milhão, para a modernização e fortalecimento da cultura do algodão. Essa atividade é parte do projeto "Apoio ao Desenvolvimento do Setor Cotonícola nos Países do Cotton-4 (Benin, Burkina Faso, Chade e Mali)", e aconteceu em virtude do interesse mútuo entre as partes no fortalecimento da cooperação Sul-Sul, principalmente na área agrícola tropical onde a Embrapa conquistou 
referência mundial. Como diz Barbosa ${ }^{26}$ : "O Projeto Cotton-4 consiste no apoio do governo brasileiro com fins a contribuir para o aumento da competitividade da cadeia produtiva do algodão nos países do C-4 à luz dos efeitos combinados das práticas de subsídios e da desvalorização da moeda norte-americana no contexto da Rodada de Doha”. E mais: “As atividades centrais do projeto se convergem na revitalização da Estação Experimental de Sotuba no Mali, que funcionará como Unidade Modelo de Validação e de Demonstração, e na capacitação de pesquisadores do C-4 em centros de pesquisa da Embrapa Algodão e outros centros de excelência do Brasil, bem como em atividades na Estação Experimental”, detalha o consultor. $^{27}$

\subsection{AMÉRICA DO SUL}

A entrada da América do Sul na agenda de prioridades da política externa brasileira é processo historicamente recente, que ocorreu em simultâneo com o "adensamento" da agenda de interesses brasileiros na região e foi incentivado, nos últimos tempos, por eventos que são reveladores das intensas transformações pelas quais vêm passando os países da região.

Os interesses brasileiros na América do Sul são hoje variados e crescentes, envolvendo atores diversificados. A região absorve cerca de $20 \%$ das exportações brasileiras e é um destino importante para as manufaturas; os investimentos de empresas brasileiras têm aumentado de forma expressiva nos últimos anos; e expandem-se os fluxos migratórios intrarregionais que têm o Brasil como origem e como destino e a integração energética regional, que deu seus primeiros passos ainda nos anos 1990.

A questão ambiental, o papel da Amazônia e a expansão do ilícito transnacional constituem temas de interesse compartilhados pelo Brasil e vários de seus vizinhos. Mais recentemente, o tema da mudança climática vem ganhando importância na região e o último relatório do Intergovernamental Panel on Climate Change (IPCC) aponta a elevada vulnerabilidade da América do Sul ao aquecimento global e seus efeitos. Historicamente, a tradição diplomática do país confere pouca importância às relações do Brasil com a América

\footnotetext{
${ }^{26}$ BARBOSA, Sebastião. Consultor responsável pela execução do projeto.

${ }^{27}$ Resumo executivo da Secretaria de Relações Internacionais da Embrapa. 2008
} 
do Sul. Essa tendência começa a mudar a partir dos anos 1990, com a gradual promoção da região na escala de prioridades da política externa brasileira ${ }^{28}$.

De acordo com Rubens Barbosa, a América do Sul - descrição geográfica mais apropriada do ponto de vista dos interesses brasileiros do que América Latina, denominação com viés mais político - representa o espaço territorial onde o peso específico do Brasil é preponderante sob qualquer critério, seja o território, a população, os recursos naturais, a indústria ou o avanço tecnológico.

Nenhum país, por mais poderoso que seja e por mais globalizada que seja a sua economia, pode deixar de dar atenção à sua vizinhança por razões de parceria comercial, mas, sobretudo, por uma questão de exigência política. Somente desse modo será capaz de acompanhar e entender as transformações regionais que afetam seus interesses. É o que mostram os exemplos dos EUA com relação ao México e ao Canadá, na América do Norte, e o da China com sua vizinhança asiática.

O mapa político e o cenário econômico na América do Sul estão sob profundas transformações. A emergência de movimentos sociais, do poder indígena e de novas lideranças fez ressurgir como foco principal um acentuado apelo popular nacionalista, antiglobalizante e de forte viés antiamericano, cujo epicentro são os países andinos, especialmente a Bolívia, o Equador e a Venezuela. Esse fenômeno político se dá no quadro de sociedades que se caracterizam por níveis elevados de pobreza e desigualdade e de economias que se veem beneficiadas pela explosão dos preços internacionais das suas poucas commodities de exportação, ensejando processos de estatização dos recursos naturais e polarização política interna. Os efeitos ideológicos do fenômeno político em questão transbordam as fronteiras dos países mencionados.

A esse ingrediente somam-se outros na redefinição dos cenários em que opera a política externa brasileira na América do Sul. A presença da China, a expansão dos laços econômico-comerciais dos países sul-americanos do lado do Pacífico com os países asiáticos e a forma pela qual está evoluindo o relacionamento dos países da região com os EUA são desafios adicionais para os formuladores da política externa brasileira.

Os governos anteriores, nos últimos vinte anos atribuíram grande prioridade à América do Sul e ao processo de integração regional. No governo Lula, o que mudou foi a maior ênfase dada aos objetivos tradicionais e a forma pela qual o Brasil interage com seu

\footnotetext{
${ }^{28}$ Força-Tarefa O Brasil na América do Sul . 2007
} 
entorno geográfico. A prioridade declarada pela região e pela integração regional é uma das três principais linhas de atuação do Itamaraty nos dois governos Lula, sendo as outras a busca de um assento permanente no Conselho de Segurança das Nações Unidas e as negociações comerciais multilaterais da Organização Mundial de Comércio no âmbito da Rodada de Doha.

Nota-se, nos últimos meses, que a atual política externa passou a dar mais ênfase ao relacionamento bilateral com projetos de cooperação, em diversas áreas, com cada um dos vizinhos, deixando para um segundo plano os esforços de integração regional. Isso se deve, provavelmente, às frustrações registradas com a efêmera experiência da Comunidade Sulamericana de Nações (CASA), que a diplomacia brasileira esforçou-se por promover e que contou com a indiferença dos demais parceiros do Mercosul, bem como à difícil concretização da União de Nações Sul-americanas (Unasul), patrocinada por Chávez, mas até o momento sem acordo quanto ao convênio constitutivo ${ }^{29}$.

Tabela 3 - Projetos de Cooperação com países da América do Sul

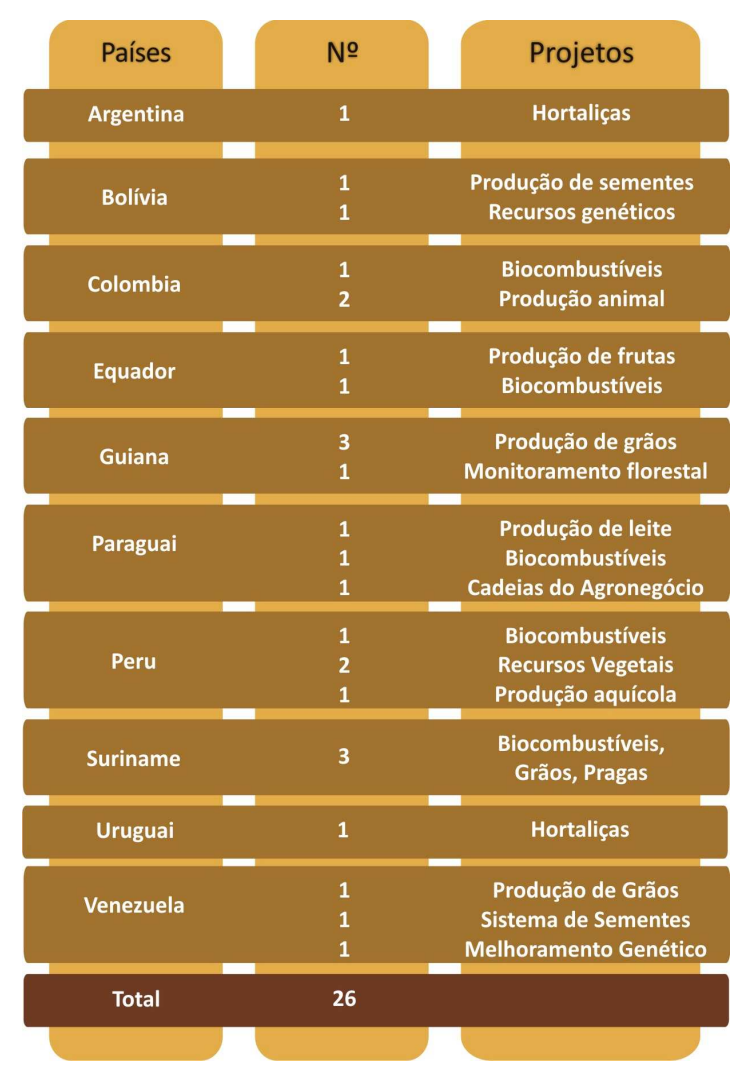

Fonte: Secretaria de Relações Internacionais- Embrapa - 2009 
A Tabela 3 identifica a atual e intensa participação da Embrapa nas ações de política externa do governo federal, dando suporte técnico para os inúmeros projetos pontuais de cooperação técnica firmados com países da América do Sul.

\subsection{ESCRITÓRIO DA EMBRAPA NA VENEZUELA}

A abertura de um escritório da Embrapa na Venezuela deveu-se a uma ação estratégica do atual governo de reaproximação política com aquele país, que apresenta sérias dificuldades para aperfeiçoar sua estrutura rural e garantir o abastecimento do mercado interno. Identificase este país como grande importador de alimentos do Brasil. Até outubro de 2007, a Venezuela comprou US\$ 860 milhões em carnes, leite, soja, frutas e derivados, um resultado 54,3\% superior ao de igual período de 2006.

A Embrapa atua na transferência de tecnologia para a adaptação de cultivares de pastagens e de algumas raças de gado leiteiro às condições climáticas da Venezuela, já que o país sofre com a escassez de lácteos, já que a tentativa de importação do gado europeu da Argentina se mostrou inviável devido à inadequação climática. A parceria com a Embrapa também inclui pesquisas para o desenvolvimento de variedades de soja destinada à ração animal e de sistemas de criação para aves. A empresa planeja treinar e capacitar pesquisadores locais, além de proporcionar a geração de negócios como a venda de sementes certificadas e processos de produção específicos. No Cerrado venezuelano, que faz fronteira com Roraima, 500 mil hectares foram destinados ao plantio de grãos e frutas. Agricultores familiares serão treinados em tratamento termoquímico de frutas para processamento agroalimentar.

Essas ações têm o objetivo de contribuir para a redução do êxodo rural, graças ao melhoramento da qualidade de vida, da integração ao redor de um projeto para as famílias rurais e indígenas, ao incremento à produção e diversificação para o consumo próprio, ao abastecimento de mercados locais, à incorporação de mão de obra local e, em geral, ao fortalecimento da atividade agrícola de acordo com a especificidade de cada localidade ${ }^{30}$.

Em 2008 houve a implantação do projeto de estruturação do Serviço Nacional de Sementes do país, no valor de US\$ 52 milhões, que pretende contribuir para a elaboração do

30 ZANATTA, Mauro. 2007 
programa de produção de sementes e do programa de melhoramento genético de forrageiras. $\mathrm{Na}$ área animal, pretende-se trabalhar num programa que vise à definição de estratégias de diagnóstico e controle de enfermidades bovina, ovina e caprina e a produção tecnificada de aves nas chamadas unidades de produção socialistas.

O Governo da Venezuela fez um acordo com a empresa brasileira Campo - referência na expansão da cultura de soja no Cerrado brasileiro - para preparar, com apoio da Embrapa, em dez anos, 600.000 hectares de soja, começando com 15.000 hectares.

Existe a programação para iniciar em 2010 o Projeto de Desenvolvimento Agrário para o país, que é um projeto de ordem social e tem o objetivo de fixar o homem à terra e desenvolver a agricultura nacional. O governo venezuelano contratou a empresa de engenharia Odebrecht para construir a infraestrutura de irrigação de 20 mil hectares e para construir 11 mil casas populares onde serão assentadas as famílias dos agricultores que trabalharão na terra, além de casas de vegetação, galpão para recebimento e preparo de hortaliças e frutas, currais, barracão de ordenha e usinas de beneficiamento de leite ${ }^{31}$.

\subsection{AMÉRICA CENTRAL E CARIBE}

As relações econômicas, políticas e culturais entre o Brasil e os cinco países da América Central - termo que se refere à Guatemala, El Salvador, Honduras, Nicarágua e Costa Rica -, durante o século XX, demonstram uma tendência orientada para uma gradual convergência de interesses, cordialidade e fortalecimento dos diferentes vínculos. De fato, trata-se de um relacionamento quase-centenário, amistoso, construtivo e promissor; porém, que ainda na atualidade continua sendo relativamente modesto ${ }^{32}$.

\footnotetext{
${ }^{31}$ www.embrapa.br/a_embrapa/labex/venezuela/Escritorio_Venezuela. Acessado em março/2010
} 


\subsubsection{Embrapa Américas}

A Embrapa irá instalar no primeiro semestre de 2010 um escritório na cidade do Saber, no Panamá, que será denominada Embrapa Américas. O seu objetivo é apoiar iniciativas voltadas ao desenvolvimento de competências, à segurança alimentar e à garantia da pauta de exportação, entre outros pontos, no México, América Central, Caribe e Região Andina.

Esta extensão da empresa atuará em três pilares principais: plataforma de pesquisa e desenvolvimento, transferência de tecnologia e negócios tecnológicos. O formato será bem diferente dos Laboratórios Virtuais da Embrapa no Exterior (Labex), que tratam especificamente de pesquisa de ponta, e dos "escritórios" instalados na África e na Venezuela, ambos focados na transferência de tecnologia.

Embora haja a previsão de uma sede, poderão ser instaladas outras equipes em países diferentes, caso haja interesse no estabelecimento de uma plataforma de pesquisa, cujo conhecimento esteja sendo desenvolvido fora do Panamá. Como exemplo destaca-se Monterrey (no México) e San Jose (na Costa Rica) que têm interessantes programas em biotecnologia e poderiam sediar iniciativas nesse tema.

A Embrapa Américas contará com uma equipe composta de um coordenador e de um especialista em transferência e negócios tecnológicos. Outra novidade deste modelo é que, ao longo do tempo, haverá o deslocamento de pesquisadores para atuar na representação por períodos de curto, médio e longo prazo (até seis meses, no máximo um ano e meio e três anos, respectivamente), dependendo da necessidade.

O trabalho a ser realizado pela Embrapa Américas contará com o suporte das instituições de pesquisa e de desenvolvimento que trabalham na região - como o Grupo Consultivo de Pesquisa Agropecuária Internacional (CGIAR), Instituto Interamericano de Cooperação para a Agricultura (IICA) e Organização das Nações Unidas para a Agricultura e Alimentação (FAO). As organizações financiadoras serão o Banco Interamericano de Desenvolvimento (BID), Banco Mundial (BIRD) e a Agência Brasileira de Cooperação do

\footnotetext{
32 ÀVILA, Carlos Federico Domingues. 2003
} 
Ministério das Relações Exteriores (ABC/MRE). A nova representação irá cumprir meta estabelecida no Programa de Fortalecimento e Crescimento da Embrapa (PAC Embrapa). ${ }^{33}$

\subsubsection{Projetos Estruturantes no Haiti}

O projeto de revitalização de uma fazenda do Ministério da Agricultura, dos Recursos Naturais e do Desenvolvimento Rural do Haiti (MARNDR), financiado pela ABC, tem como objetivo principal a validação de tecnologias e a realização de treinamentos para técnicos e produtores do Haiti. A iniciativa, que conta com a participação do Instituto Interamericano de Cooperação para a Agricultura (IICA), prevê a instalação de Unidades Demonstrativas (UDs) de milho, arroz, feijão e mandioca, em conjunto com os centros da Embrapa que trabalham com esses produtos, além da construção de um centro de treinamento.

Pesquisadores da Embrapa estão trabalhando na drenagem de uma área alagada de quase 10 ha para viabilizar seu uso como área agricultável. Com a realização de todas as obras previstas, a fazenda passará a ter características de área demonstrativa de tecnologia como as que existem no Brasil.

Outro projeto está sendo executado na região de Kenscoff desde 2008. As atividades pretendem fortalecer o setor produtivo da região, com a adoção de tecnologias sustentáveis de produção e levantamento de informações estratégicas. Para 2010, existe a previsão para a instalação de Unidades Demonstrativas em diversas áreas, com materiais e tecnologias de produção de hortaliças, além da realização de um seminário nacional, reunindo técnicos e produtores de todo o país.

Outra ação já realizada é o levantamento socioeconômico da cadeia produtiva de hortaliças no Haiti, com o objetivo de identificar políticas públicas ou ações internacionais a serem implantadas na região ${ }^{34}$.

\footnotetext{
33 www.embrapa.br/imprensa/noticias/2009/novembro/1a-semana/embrapa-americas-sera-instalada-nopanama/?searchterm=Embrapa americas

34 www.cnph.embrapa.br/historico. Acessado em março/2010
} 


\section{CONCLUSÃO}

As empresas brasileiras passaram por um processo de internacionalização que se iniciou nos anos 1980, a partir das transformações decorrentes do processo de globalização. Essa ampliação das relações fora dos limites geográficos brasileiros começou no século XV e teve como fatores dinamizadores a revolução industrial e as inovações tecnológicas em vários setores, ocorridas no século XIX, bem como o desenvolvimento das comunicações e da indústria de tecnologia da informação, no século XX. Com a prática do liberalismo econômico utilizada por diversos países, houve a ampliação dos mercados consumidores e o aumento da concorrência. As empresas que quisessem se manter competitivas tinham que iniciar seu processo de internacionalização, por meio da produção de excedente para exportação, já que havia incentivos decorrentes da estratégia de desenvolvimento da Cepal.

A Embrapa, criada no início da década de 1970, teve o seu processo de internacionalização iniciado a partir do envio de um grande número de técnicos para capacitação em universidades europeias e norte-americanas com recursos internacionais. Esse modelo de importação de conhecimentos, muito usual na década de 1980, contribuiu, efetivamente, após um processo de adaptação do conhecimento à realidade nacional, para o enorme avanço do desenvolvimento da agricultura brasileira. Essa experiência solidificada passou a ser utilizada nas diversas regiões do território nacional, trazendo resultados surpreendentes, tais como a utilização da região dos Cerrados para plantio de soja e o aumento da produção de grãos, hortaliças, leite e carnes bovina, suína, e frango em várias regiões do país, fatores importantes para o aumento da produtividade agropecuária e para o aumento do volume de exportações.

Houve, portanto, na Embrapa, a mesma motivação para o início do processo de internacionalização de empresas privadas, qual seja, a necessidade de se manterem competitivas. A capacitação técnica no exterior proporcionou não apenas resultados referentes à introdução de novas tecnologias no processo produtivo agropecuário, como ajudou no desenvolvimento de novas parcerias internacionais com universidades e organismos multilaterais, facilitando a captação de recursos para o desenvolvimento de novos projetos. Numa segunda etapa, na década de 1990, houve a criação dos Labex, em parceria com institutos de pesquisa norte-americanos e europeus, com o objetivo de realizar pesquisa de interesse comum entre as partes e de fazer prospecção de tecnologias inovadoras, além de 
buscar uma inserção em redes de conhecimento. Essas ações consolidaram o reconhecimento da competência da empresa junto à comunidade científica internacional.

A partir de 2003, a Embrapa teve incremento significativo na participação em missões oficiais, viagens presidenciais, missões de cooperação bilateral e multilateral, e visitas de prospecção do governo federal. Destacam-se alguns fatores que contribuíram para o processo de aceleração da internacionalização da Embrapa nesse período: a credibilidade alcançada como empresa de pesquisa no meio acadêmico internacional, a partir dos resultados alcançados no desenvolvimento da agropecuária tropical; a nova estratégia da política externa brasileira de intensificar as parcerias com os países do hemisfério Sul, com condições de solo e clima semelhantes aos do Brasil; a estabilidade econômica alcançada pelo país, garantindo recursos para uma maior colaboração com os países emergentes; a determinação dos gestores públicos da política externa em assumir uma ação de liderança na região sul-americana; e o fortalecimento das relações com o continente africano, oferecendo cooperação técnica para ajudar a desenvolver a agropecuária na região.

O processo de transferência de tecnologia realizado pela Embrapa nos diversos contextos internacionais ajuda a empresa a validar suas tecnologias e a aprimorá-las, diante de novos elementos que demandam novas soluções, tornando essas tecnologias cada vez mais competitivas no cenário internacional. $\mathrm{O}$ aumento no volume de projetos executados pela empresa passou a demandar ações internas de planejamento e de estruturação da área de relações internacionais para viabilizar um melhor atendimento de demandas. Houve a ampliação do quadro técnico de funcionários para organizar o fluxo de demandas por cooperação técnica bilateral recebida do MRE, da ABC, e das novas representações abertas no exterior.

A seguir, são apresentadas duas recomendações relevantes para o aprimoramento do processo de internacionalização da Embrapa:

Avaliar os impactos socioeconômicos da cooperação técnica prestada pela empresa ao longo do tempo, quais sejam: identificar mudança no patamar competitivo da agricultura dos países ao longo do tempo; verificar o aumento da renda das famílias rurais e agrícolas e sua fixação no campo; avaliar a capacidade de abastecimento do mercado interno com produtos agropecuários produzidos nos países; e avaliar a contribuição para a garantia da segurança alimentar da população.

Contribuir para o aprimoramento da estrutura institucional pública dos países recipiendários da cooperação técnica, a fim de garantir que as ações realizadas tenham 
continuidade e possam contribuir efetivamente para a formação/capacitação de uma massa crítica de pesquisadores e de instituições públicas preparadas para enfrentar os desafios do desenvolvimento rural sustentável.

Como estratégia de atuação, destaca-se a importância de se trabalhar no estreitamento de relações das unidades da Embrapa situadas próximo às fronteiras com os países vizinhos para a construção de soluções a problemas comuns, sob a coordenação da Secretaria de Relações Internacionais da Embrapa.

A Embrapa pode ainda fazer uso do acúmulo de experiências adquiridas pelos pesquisadores que já participaram da execução de projetos de cooperação técnica, para identificar novos temas que estão sendo pesquisados por outros países do hemisfério Sul, que podem contribuir para o aprimoramento tecnológico da agropecuária brasileira.

Considera-se que a hipótese desta monografia foi comprovada, uma vez que o processo de internacionalização da Embrapa iniciado com a importação de conhecimento das universidades e instituições de pesquisa dos países do hemisfério Norte, após a consolidação da sua competência técnica e o reconhecimento internacional, a transformou em exportadora de conhecimento a países do hemisfério Sul. Fica evidente o papel relevante da empresa, mediante o incremento da participação em ações cada vez mais substanciais na transferência tecnológica agropecuária para a execução da política externa brasileira. 


\section{Referências Bibliograficas}

MOLLO, M. L. R. . Globalização da Economia; Exclusão Social e Instabilidade Monetário-Financeira. POLÍTICA COMPARADA, BRASÍLIA, v. I, n. 02, 1997.

LIMA, Maria Regina Soares de. A política externa brasileira e os desafios da cooperação Sul-Sul; Revista Brasileira de Política Internacional. Print version ISSN 0034-7329, Rev. Bras. Polít. Int., vol.48, no.1, Brasília, Jan./June 2005;

CASSANO, Francisco Américo; NETO, Petrônio de Tilio; VORMITTAG, Carlos Francisco; JUNIOR, Amadeu Nosé; WIESEL, Raul Miguel. Internacionalização de empresas brasileiras a partir de 1990. (www.ead.fea.usp.br/Semead/10semead/sistema/ resultado/.../309).Agosto 2007

SOUTO MAIOR, Luiz A. P. Desafios de uma política externa assertiva. Rev.bras.polít. int. vol.46 no.1 Brasília Jan./June 2003

BNDES, Caracterização do processo de internacionalização de grupos econômicos privados brasileiros. Rio de Janeiro, nov. 1995 (Série Pesquisas Empresariais, 1)

CORREA, Daniela; LIMA, Gilberto Tadeu. Internacionalização produtiva de empresas brasileiras: caracterização geral e indicadores. Informações Fipe, n. 319, abril 2007;

DIAS, V. V. Las empresas brasileñas: internacionalización y ajuste a la globalización de los mercados. Cepal 1994.

DUNNING, J. H. Toward an eclectic theory of international production: some empirical tests. Journal of International Business Studies, v. 11, n. 1, 1980.

DUNNING, J. H.; Hoesel, R.; Narula, R. Third World multinationals revisited: new developments and theoretical implications. University of Reading, 1997 (Discussion Papers in International Investment and Management, 227).

GOUlART, L.; Brasil, H. V.; Arruda, C. A. A evolução na dinâmica de internacionalização. Revista Brasileira de Comércio Exterior, Rio de Janeiro, 2000.

LOPEZ, A. El caso brasileño. In: Chudnovsky, D.; Kosakoff, B.; Lopez, A. (eds.), Las multinacionales latinoamericanas: sus estrategias en un mundo globalizado. Buenos Aires: Fondo de Cultura Económica, 1999.

VEIGA, P. M.; IGLESIAS, R. Promoção de exportações via internacionalização das firmas de capital brasileiro. $I n$ : Pinheiro, A. C.;

MARKWALD, R.; Pereira, L. V. (orgs.), O desafio das exportações. Rio de Janeiro: BNDES, 2002.

CAMPOS, Elisa. As empresas mais internacionalizadas do Brasil / Investimento fora do país alcançou US\$20,5 bilhões em 2008, a segunda marca mais alta da história - Revista Época/Empresas / Investimento - 10/08/2009 
FILHO, Pio Penna. - Artigo: A África nas Relações Internacionais - Novas possibilidades ou nova partilha?. ( http://meridiano47.info/2008/12/31/a-africa-nas-relacoes-internacionais$\%$ E2\%80\%93-novas-possibilidades-ou-nova-partilha-por-pio-penna-filho/).

BUENO, Chris. Cooperação entre Brasil e África. Revista Com Ciência. Publicação da Sociedade Brasileira para o Progresso da Ciência (SPBC) em parceria com o Laboratório de Estudos Avançados em Jornalismo da Unicamp. N 97, abril de 2008

Força - Tarefa. O Brasil na América do Sul;Relatório Final;junho 2006. Atividades coordenadas por Maria Regina Soares de Lima, Pedro da Motta Veiga e Sandra Polônia Rios. www.iadb.org/intal/.../uploads/.../p_Foro_INTAL_2007_11_01_CINDES.pdf.

BARBOSA, Rubens. A Política Externa do Brasil para a América do Sul e o Ingresso da Venezuela no MERCOSUL.Revista Interesse Nacional - Edição nº 8/2008. www.interessenacional.com/artigos-integra.asp?cd_artigo $=9$ -

ZANATTA, Mauro. Embrapa terá operações na Venezuela.Revista Jornal Valor Econômico, 13/12/2007. www.cpact.embrapa.br/linha/antigo/linha598.pdf

AVILLA, Carlos Federico Dominguez . O Brasil frento ao conflito regional na América Central. Rev. bras. polít.int. vol.46 no.1 Brasília Jan./June 2003 